Document downloaded from:

http://hdl.handle.net/10251/37041

This paper must be cited as:

Bonastre Cano, JA.; Molina Puerto, J.; Del Río García, Al.; Galván, J.C. ; Cases, F. (2011). Study of the electrical properties of novel hybrid organic-inorganic conducting textiles of polypyrrole-phosphotungstate-polyester using Electrochemical Impedance Spectroscopy. Synthetic Metals. 161:1958-1965. doi:10.1016/j.synthmet.2011.07.002.

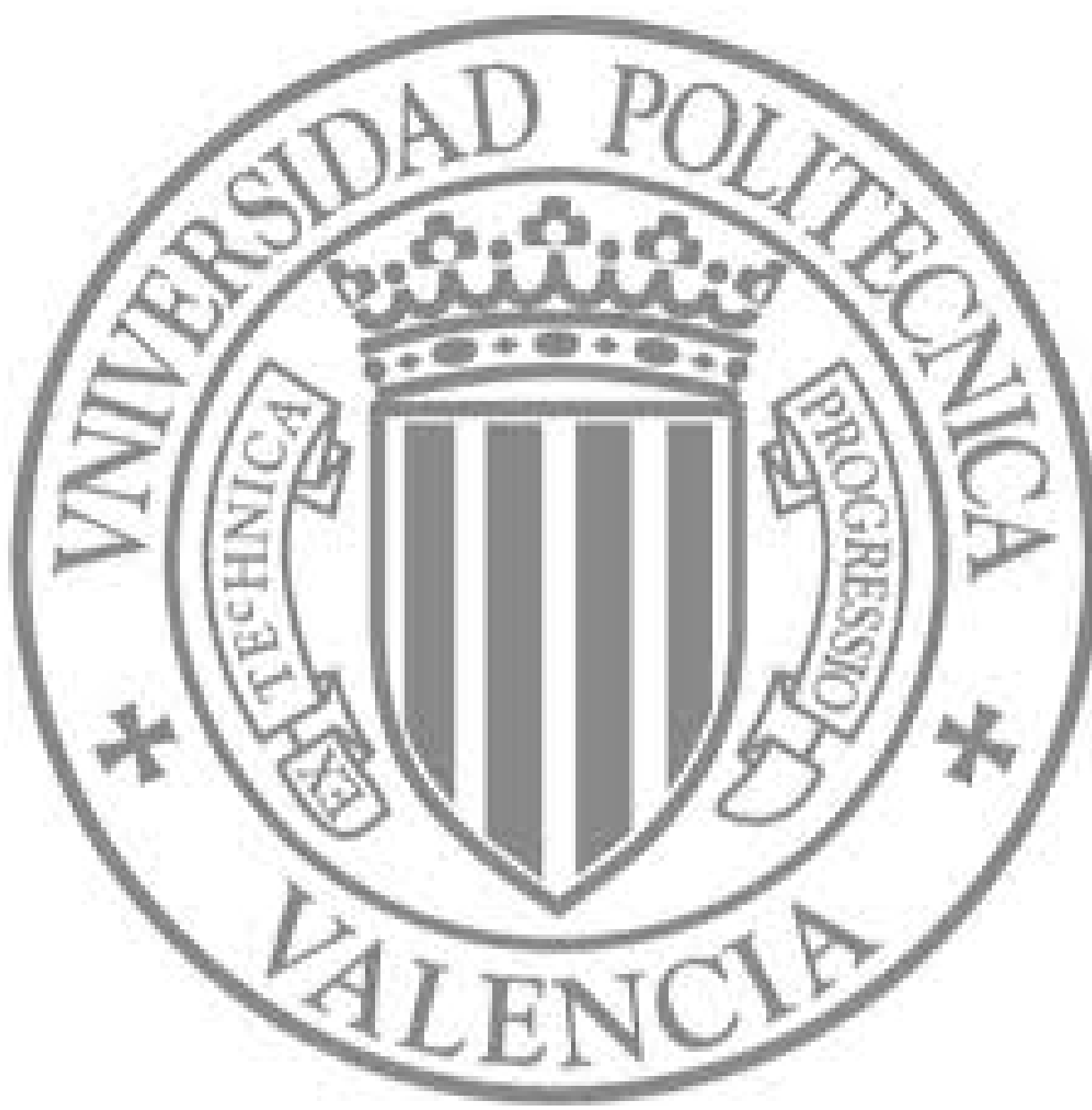

The final publication is available at

http://dx.doi.org/10.1016/j.synthmet.2011.07.002

Copyright Elsevier 
Document downloaded from:

http://hdl.handle.net/10251/37041

This paper must be cited as:

Bonastre Cano, JA.; Molina Puerto, J.; Del Río García, Al.; Galván, J.C. ; Cases, F. (2011). Study of the electrical properties of novel hybrid organic-inorganic conducting textiles of polypyrrole-phosphotungstate-polyester using Electrochemical Impedance Spectroscopy. Synthetic Metals. 161:1958-1965. doi:10.1016/j.synthmet.2011.07.002.

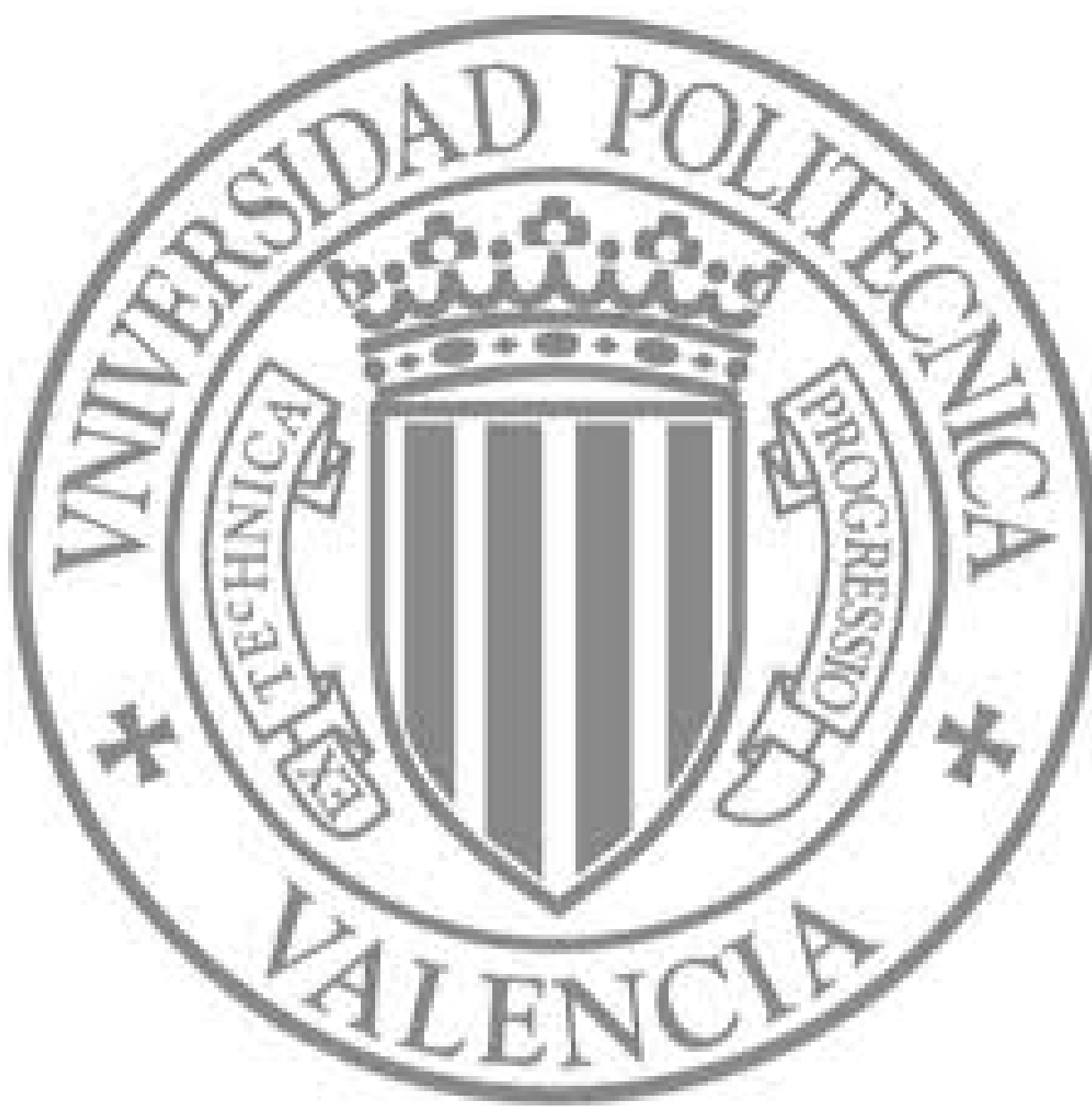

The final publication is available at

http://dx.doi.org/10.1016/j.synthmet.2011.07.002

Copyright Elsevier 


\title{
Study of the electrical properties of novel hybrid organic-inorganic conducting textiles of polypyrrole-phosphotungstate-polyester using Electrochemical
} Impedance Spectroscopy

\author{
J. Bonastre ${ }^{\mathrm{a}}$, J. Molina ${ }^{\mathrm{a}}$, A.I. del Río ${ }^{\mathrm{a}}$, J.C. Galván ${ }^{\mathrm{b}}$, F. Cases ${ }^{\mathrm{a}, *}$ \\ ${ }^{a}$ Departamento de Ingeniería Textil y Papelera, EPS de Alcoy, Universitat Politècnica \\ de València, Plaza Ferrándiz y Carbonell s/n, 03801 Alcoy, Spain \\ ${ }^{b}$ Centro Nacional de Investigaciones Metalúrgicas, CSIC \\ Avda. Gregorio del Amo 8, 28040 Madrid, Spain
}

\begin{abstract}
The electrical properties of novel hybrid organic-inorganic conducting fabrics of polyester (PES) coated with polypyrrole- $\mathrm{PW}_{12} \mathrm{O}_{40}{ }^{3-}$ (PPy-POM) have been tested for dry samples and specimens immersed in different $\mathrm{pH}$ solutions $(1,7,13)$. Electrical properties changes were measured by means of Electrochemical Impedance Spectroscopy (EIS). This study showed that organic-inorganic PES-PPy-POM conducting textiles act as electronic conductors with semiconducting nature. The electrical conductivity was measured for different temperatures and a value of $44.4 \mathrm{meV}$ was obtained for the activation energy by means of Arrhenius model. Samples immersed in solution increased their conductivity in more acid solutions due to polypyrrole protonation. As acidity increased protonation and oxidation state of polypyrrole chains, a greater diffusion of counter-ions was observed since the hybrid conducting textiles presented a more swollen and porous structure. Counter-ion
\end{abstract}


exchange was higher in more acid solutions since more charge was needed to compensate the positive charge of more oxidized polypyrrole chains. A catalytic effect might be expected for the $\mathrm{H}^{+}$reduction for this new organic-inorganic electrode material in acid media.

Keywords: Conducting fabrics, organic-inorganic, polypyrrole, phosphotungstate, EIS.

* Corresponding author. Tel.: +34 9665284 12; fax: +34 966528438 .

E-mail address: fjcases@txp.upv.es (Prof. F. Cases).

\section{Introduction}

Conducting polymers as polypyrrole have been studied during the last three decades due to their promising properties as revolutionary materials [1]. One very interesting application of conducting polymers is electrical conducting textiles. Different methods have been employed to produce conducting textiles, such as the synthesis of conducting polymers on the fabrics [2-10], the chemical metallization of fibers [11], etc. Applications of conducting textiles are varied and numerous; such as: antistatic materials [2], gas sensors [3], biomechanical sensors [4], electrotherapy [5, 6], heating devices [7-9] or microwave attenuation [10].

During the formation of polypyrrole, positive charges are created in the polypyrrole structure. Negative charges provided by a counter-ion compensate the positive charges to maintain the electroneutrality principle. If the counter-ion is expelled from the structure (dedoping), there is a great loss of its electrical properties. Low size anions 
such as $\mathrm{Cl}^{-}$have been employed as counter-ions, but their stability is low [10]. To prevent this phenomenon, bulky anions with high molecular size have been employed in bibliography. Typical counter-ions employed in the production of polypyrrole-based conducting fabrics are organic molecules with high size; such as: anthraquinone sulfonic acid (AQSA) [3, 8, 10, 12-15], dodecylbenzene sulfonic acid (DBSA) [2, 13], p-toluene sulfonic acid (PTSA) [3, 10, 13, 16, 17], naphthalenedisulfonic acid (NDSA) $[4,10,13]$, benzenesulfonic acid (BSA) [5, 18], naphthalenesulfonic acid (NSA) [10, $16,17]$ and anthraquinone disulfonic acid (AQDSA) $[19,20]$. If the size of the counterion is high, its diffusion is prevented and it remains in the polypyrrole structure [21]. Polyoxometalates, POMs, are also anions of high volume and charge and present electrochemical activity and catalytic properties. POMs are oxide clusters whose size and solubility have caused them to be traditionally considered within the framework of molecular chemistry. They are indeed complex molecules with several metallic ions coordinated by shared oxide ions, forming a highly symmetrical metal oxide cluster [1]. Phosphotungstic acid, $\mathrm{H}_{3} \mathrm{PW}_{12} \mathrm{O}_{40}(\mathrm{POM})$, has been used in this work as a counter-ion to be immobilized within the polymeric matrix. The molecular structure of the phosphotungstic acid is shown in Fig. 1 [22].

\section{Fig. 1. Molecular structure of the phosphotungstic acid}

In addition, POMs present the possibility to produce a hybrid material when combined with conducting polymers such as polypyrrole. Therefore, a hybrid material with combined properties (organic-inorganic) is synthesized. The molecular material formed between polypyrrole and the phosphotungstate anion is showed in Fig. 2 [23]. 
Fig. 2. Idealized scheme of the structure of the molecular material formed between polypyrrole and the $\mathrm{PW}_{12} \mathrm{O}_{40}{ }^{3-}$ anion.

One of the applications that our group is investigating is the employment of organicinorganic PPy-POM conducting fabrics in catalysis; or as a support with high surface area to electrodeposit Pt nanoparticles and enhance its electroactivity [24, 25]. The employment of conducting polymers in environmental purposes has been reported [2630]. For instance, electrodes modified with conducting polymers have been used in $\mathrm{Cr}^{6+}$ (toxic) reduction to $\mathrm{Cr}^{3+}$ (not toxic) [26] or nitrites electroreduction [27]. Polypyrrole coated fabrics have been employed in the electrochemical removal of the textile dye C. I. Direct Red 80 [28]. Polyaniline/ $\mathrm{MnO}_{2}$ catalyst has been employed in the degradation of organic dyes such as Direct Red 81, Indigo Carmine and Acid Blue 92 [29, 30].

For this purpose, the objective of this work is to study the electrical properties of novel hybrid organic-inorganic PES-PPy-POM conducting textiles using EIS to measure dry samples and also immersed in different $\mathrm{pH}$ solutions. This is essential to optimize the operational $\mathrm{pH}$ range for its employment in wastewater treatment.

\section{Experimental}

\subsection{Reagents and materials}

Analytical grade pyrrole, ferric chloride, sulfuric acid, sodium sulfate, sodium hydroxide, sodium dihydrogenophosphate and disodium hydrogenophosphate were purchased from Merck. Normapur acetone was from Prolabo. Analytical grade 
phosphotungstic acid hydrate was supplied by Fluka. When needed, solutions were deoxygenated by bubbling nitrogen $\left(\mathrm{N}_{2}\right.$ premier X50S). Ultrapure water was obtained from an Elix 3 Millipore-Milli-Q Advantage A10 system with a resistivity near to 18.2 $\mathrm{M} \Omega \mathrm{cm}$.

Polyester textile was acquired from Viatex S. A. and its characteristics were: fabric surface density, $140 \mathrm{~g} \mathrm{~m}^{-2}$; warp threads per cm, 20 (warp linear density, $167 \mathrm{dtex}$ ); weft threads per cm, 60 (weft linear density, 500 dtex). These are specific terms used in the field of textile industry and their meaning can be consulted in a textile glossary [31].

\subsection{Chemical synthesis of PES-PPy-POM}

Chemical synthesis of organic-inorganic PPy-POM on polyester textiles was done as reported in our previous study [15]. The size of the samples was $6 \mathrm{~cm} \times 6 \mathrm{~cm}$ approximately. Previously to reaction, polyester was degreased with acetone in ultrasound bath and washed with water. Pyrrole concentration employed was $2 \mathrm{~g} \mathrm{~L}^{-1}$ and the molar ratios of reagents employed in the chemical synthesis bath were pyrrole: $\mathrm{FeCl}_{3}$ : POM (1: 2.5: 0.2). The next stage was the adsorption of pyrrole and counter-ion $(\mathrm{POM})(\mathrm{V}=200 \mathrm{ml})$ on the fabric for $30 \mathrm{~min}$. At the end of this time, the $\mathrm{FeCl}_{3}$ solution $(\mathrm{V}=50 \mathrm{ml})$ was added and oxidation of the monomer took place during $150 \mathrm{~min}$. Adsorption and reaction took place in a precipitation beaker and in an ice bath without stirring. The reason for carrying out the synthesis at low temperatures is that the polymer obtained presents better properties at lower temperatures. Polypyrrole synthesized at lower temperature exhibits longer conjugation length, fewer structural defects, higher doping level [32] and consequently, higher conductivity [32, 33]. Higher temperatures increase the reaction rate, more oligomers are formed per unit of time and 
the transport is not effective onto fiber surface [12]. When this happens, polypyrrole particles are formed in solution. Decreasing the temperature of the solution, the formation of polypyrrole particles in solution is lowered. The temperature when the oxidant is added varies since pyrrole polymerization begins. As this is an exothermal reaction and heat is generated, the temperature of the synthesis solutions rises [34]. The ice bath minimizes significant temperature changes. The conducting fabric was washed with water to remove PPy not joined to fibers. The conducting textile was dried in a desiccator for at least $24 \mathrm{~h}$ before measurements. The weight increase was measured obtaining a value between $7-10 \%$.

\subsection{Electrochemical Impedance Spectroscopy characterization with temperature}

EIS measurements were employed to obtain the conductivity of the PES-PPy-POM sample. An electrochemical interface Solartron 1286 was employed to control the potential and a Solartron 1253 Gain-Phase analyzer was employed to perform EIS measurements in the $10^{4}$ to $10^{-2} \mathrm{~Hz}$ frequency range. The amplitude of the sinusoidal voltage employed was $\pm 10 \mathrm{mV}$. Each measurement was carried out at a constant imposed potential equal to the stabilized open circuit potential at the beginning of the experiment. EIS measurements were also carried out at different temperatures (25-60 $\left.{ }^{\circ} \mathrm{C}\right)$. The impedance measurements were carried out using a 2-probe setup in a GF-1000 sample cell supplied by Equipos Instrumentación y Control S.L. (EIC). Fig. 3 shows the GF-1000 sample cell employed. A furnace Carbolite CTF 12/65/550 with a Eurotherm 2408 temperature controller was employed to control the temperature with the Settemp 3.0 software (developed by EIC). A scheme of connections for impedance measurements with temperature is shown in Fig. 4 [35]. To analyze quantitatively the 
electrochemical behavior of the samples, the experimental impedance data were modeled and fitted to data generated by using suitable electrical equivalent circuits and a non-linear least squares fitting minimization method; included in the ZPlot/ZView software (3.1c version) from Scribner Associates Inc, Southern Pines, NC, USA.

Fig. 3. Photograph of GF-1000 sample cell (up to $1000^{\circ} \mathrm{C}$ ): with water recirculation for cooling.

Fig. 4. Scheme of connections for impedance measurements with temperature.

\subsection{EIS study of organic-inorganic PES-PPy-POM fabrics in different pH solutions}

Different samples of PES-PPy-POM $(2 \mathrm{~cm} \times 2 \mathrm{~cm})$ were analyzed in different $\mathrm{pH}$ solutions. The solutions employed were: $0.5 \mathrm{M} \mathrm{H}_{2} \mathrm{SO}_{4}(\mathrm{pH} \sim 0)$, phosphates buffer +0.1 $\mathrm{M} \mathrm{Na}_{2} \mathrm{SO}_{4}(\mathrm{pH} \sim 7)$ and $0.1 \mathrm{M} \mathrm{NaOH}+0.1 \mathrm{M} \mathrm{Na}_{2} \mathrm{SO}_{4}(\mathrm{pH} \sim 13)$. After $1 \mathrm{~h}$ of contact with the different $\mathrm{pH}$ solutions, the samples were analyzed by means of EIS.

The EIS measurements were performed in the same frequency range and amplitude than in Section 2.3. The experimental results were also analyzed as in Section 2.3.

The EIS analyses for metal/PES-PPy-POM fabric/metal symmetrical configuration were measured placing a drop of mercury on a hybrid PES-PPy-POM conducting fabric placed on a stainless steel plate. The electric contact was done with a stainless steel rod contacting with the drop of mercury employing a two-electrode configuration. These measurements were performed for samples treated in $\mathrm{pH} 0$ solution in order to obtain preliminary data for fitting experimental data in asymmetrical configuration. A standard three-electrode design was employed for the asymmetrical configuration metal/PESPPy-POM/electrolyte system. In this configuration the working electrode was the 
conducting fabric placed on a stainless steel plate; the counter electrode was a stainless steel rod, and the reference electrode was an $\mathrm{Ag} / \mathrm{AgCl}(3 \mathrm{M} \mathrm{KCl})$. The electrolyte resistance data were obtained removing the textile working electrode and putting only the stainless electrode for each different $\mathrm{pH}$ solution.

\subsection{SEM characterization}

A Jeol JSM-6300 Scanning Electron Microscope was employed to observe the morphology of the samples. SEM analyses were performed using an acceleration voltage of $20 \mathrm{kV}$.

\section{Results and discussion}

\subsection{Electrochemical Impedance Spectroscopy characterization with temperature}

The EIS measurements were conducted with a temperature cell GF-1000. The sample was placed between two Pt plates of $0.8 \mathrm{~cm}^{2}$. In Fig. 5, the Bode plots for the sample of PES-PPy-POM measured at different temperatures $\left(25-60^{\circ} \mathrm{C}\right)$ are shown as example. In the upper diagram it can be seen the impedance modulus $(|\mathrm{Z}|)$ at the different frequencies. The impedance modulus gives us the resistance of the conducting fabric at the different frequencies and temperatures employed. It can be seen that as the temperature increases, the impedance modulus lowers. The equivalent circuit employed to adjust the data values was a single resistance $(\mathrm{R})$. The data were adjusted with the Zview software and the resistance of the sample at the different temperatures was obtained. These values were employed to obtain the electrical conductivity $\left(\mathrm{S} \mathrm{cm}^{-1}\right)$. 
The second diagram in Fig. 5 shows the data for the phase angle at different frequencies for the same samples of the first diagram. The sample of PES-PPy-POM showed $0^{\circ}$ for the phase angle at all the temperatures employed. This value of phase angle indicates that the material acts as a resistor with different resistances as it was shown in the first Bode plot. The phase angle for insulating materials is $90^{\circ}$, so the fabric acts as an electronic conductor.

Fig. 5. Bode plots for the PES-PPy-POM fabric at different temperatures $\left(25-60{ }^{\circ} \mathrm{C}\right)$. Measurement between two Pt electrodes $\left(0.8 \mathrm{~cm}^{2}\right)$. Frequency range from $10^{4} \mathrm{~Hz}$ to $10^{-2} \mathrm{~Hz}$

\subsubsection{Adjust to the Arrhenius model}

The electrical conductivity $\left(\mathrm{S} \mathrm{cm}^{-1}\right)$ of the samples at the different temperatures was calculated with the data of resistance, thickness of the sample $(0.017 \mathrm{~cm})$ and measured area $\left(0.8 \mathrm{~cm}^{2}\right)$. The electrical conductivity of conducting fabric of PES-PPy-POM increases with temperature as it was commented before, this indicates a semiconducting nature. This type of behavior is the typical of conducting polymers, as thermal excitation is needed to move charge carriers [36]. The opposite behavior (metallic conduction) only has been reported in ordered polyaniline for conducting polymers [37]. The electrical conductivity behavior with temperature can be explained using different models. In this section we have applied the Arrhenius model (equation 1) [3840].

$\sigma=\sigma_{0} \exp \left[-\frac{E_{a}}{k T}\right](1)$ 
Where $\sigma$ is the conductivity $\left(\mathrm{S} \mathrm{cm}^{-1}\right)$ at each temperature, $\sigma_{0}$ is the conductivity at room temperature, $\mathrm{E}_{\mathrm{a}}(\mathrm{eV})$ is the carrier activation energy and $\mathrm{k}$ is the Boltzmann constant $\left(8.61734 \cdot 10^{5} \mathrm{eV} \mathrm{K}^{-1}\right)$. The plot of $\ln (\sigma)$ vs $1000 / \mathrm{T}$ is shown in Fig. 6. As it was explained, the conductivity increased with the increase of the temperature. The data from 25 to $60{ }^{\circ} \mathrm{C}$ gives a straight line, so the data adjust to the Arrhenius model. The slope of the adjust is equal to $\mathrm{E}_{\mathrm{a}} / 1000 \mathrm{k}$, so the activation energy can be calculated from the value of the slope obtained by the linear adjust. The activation energy obtained was 44.4 meV. Similar values of activation energies have been obtained in bibliography for polypyrrole $[39,40]$.

Fig. 6. Plot of $\ln (\sigma)$ vs. 1000/T for the data obtained for a PES-PPy-POM fabric.

\subsection{EIS study of organic-inorganic PES-PPy-POM fabrics in different $p H$ solutions}

For an electroactive conducting polymer (deposited on PES; that is an electrical insulating material); in solution the following contributions can be expected to its impedance:

- An electronic charge transfer resistance between the PES-PPy-POM conducting textile and the metal tweezers.

- Charge transport within the PES-PPy-POM conducting textile: electrons, polarons, bipolarons, anions and cations. The charge transport is carried out by a coupled electron-ion transport inside the film [41].

- The ionic charge transfer resistance between the PES-PPy-POM conducting textile and the solution. 
- An ion-electron charge transfer resistance between the PES-PPy-POM conducting textile and the solution. Generally, the polymer/solution interface is an electron blocking surface when no-redox couples are in solution [42]. Nevertheless, in this work, solutions with high $\mathrm{H}^{+}$or $\mathrm{OH}^{-}$concentrations have been used. Hereby, this ion-electron charge transfer could appear and it must be taken into account.

The electrical phenomena commented previously can be modeled taking into account the equivalent circuits proposed by Nguyen Thi Le et al. and Van Schaftinghen et al. $[42,43]$. The proposed equivalent circuit is shown in Fig. 7, where the different elements have the following meanings:

Fig. 7. Equivalent circuit for metal/PES-PPy-POM/electrolyte system.

- Re: Electrolyte resistance

- Rfsi: Ionic charge transfer resistance at the PES-PPy-POM textile/solution interface corresponding to the counter-ion exchange. Cfsi: Space charge capacitance at the PESPPy-POM textile/solution interface corresponding to the counter-ion exchange.

- W: Warburg impedance due to counter-ion diffusion. W-R: Diffusion resistance. W-T: $1^{2} / \mathrm{D}(\mathrm{s})$, l: length of the diffusion layer, D: binary electron-ion diffusion coefficient. WP: Warburg exponent.

- Rfsie: Ion-electron charge transfer resistance at the PES-PPy-POM textile/solution interface with redox species.

- Rfeon: Electronic resistance of the PES-PPy-POM textile. 
- Rfion: Ionic resistance of the PES-PPy-POM textile. Cf: Capacitance in parallel associated with Rfeon and Rfion to account for dielectric properties of the PES-PPyPOM textile.

- Rmfe: Electronic charge transfer resistance corresponding to the electron exchange between the PES-PPy-POM textile and the metal tweezers. Cmfe: Space charge capacitance corresponding to the electron exchange at the metal/PES-PPy-POM textile interface.

- Rmeon: Electronic resistance of the metallic tweezers. This metal bulk resistance is near to 0 for metals.

Normally, different electrical phenomena can not be understood directly in the electrical response plotted in the Nyquist and Bode plots. Sometimes, the terms associated with the metal/sample interface and the sample/solution one are interchangeable, which makes it impossible to unambiguously attribute the respective relaxations [42]. Therefore, before measuring the electrical response for the asymmetrical configuration metal/PES-PPy-POM textile/electrolyte, the electrical response of the organic-inorganic PES-PPy-POM textile treated in $\mathrm{pH} 0$ solution was measured. A drop of mercury was placed on the hybrid PES-PPy-POM fabric which was located on a stainless steel plate employing a two-electrode configuration. These measurements were performed for samples treated in $\mathrm{pH} 0$ solution with the purpose of obtaining preliminary data for fitting experimental data in asymmetric configuration. Moreover, this symmetrical configuration metal/PES-PPy-POM textile/metal was carried out in order to understand the relaxations due to electronic and ionic resistances (ionic and electronic mixed conductivity), electronic charge transfer between metal and polymer, and ionic diffusion 
within the hybrid conducting textile, since ion-electron charge transfer from electrolyte is blocked in this system.

3.2.1. Study of the electrochemical behavior of hybrid organic-inorganic PES-PPyPOM fabrics between two metallic conductors

The impedance response for metal/PES-PPy-POM textile/metal symmetrical configuration could be defined by the following relationship proposed by Vorotyntsev et al. [41]:

$$
\begin{aligned}
& Z_{m / f / m}(\omega)=R m f e+R f+R f m e+4 t_{i}^{2} \Delta R f Z_{t h}(v) \\
& Z_{t h}(v)=v^{-1} \tanh v, \Delta R f=L(4 D C \rho)^{-1} \\
& v=\left(j \omega L^{2} / 4 D\right)^{1 / 2}
\end{aligned}
$$

where Rmfe and Rfme: electronic interfacial charge transfer resistances between the metallic tweezers and PES-PPy-POM fabric, Rf: high-frequency bulk-film resistance $\left(\right.$ Rfeon + Rfion), $\mathrm{t}_{\mathrm{i}}$ : ionic migration (high-frequency) transference number, L: film thickness, D: binary electron-ion diffusion coefficient, $\mathrm{C} \rho$ : redox capacitance per unit volume, $\omega$ : angular frequency. The last term of the first equation (2) is due to the counter-ion diffusive component in the bulk of the conducting polymer. The organicinorganic PES-PPy-POM fabric treated with $\mathrm{pH} 0$ sulfuric acid solution was placed between two metallic conductors and the EIS measurements were begun with a twoelectrode system. Figs. 8 and 9 show the Nyquist and Bode plots for this system. 
Fig. 8. Nyquist plot of a hybrid organic-inorganic PES-PPy-POM fabric placed between two metallic conductors. Exposed electrode area: $1 \mathrm{~cm}^{2}$. Frequency range from $10^{4}$ to $10^{-2} \mathrm{~Hz}$.

Fig. 9. Bode plots of a hybrid organic-inorganic PES-PPy-POM fabric placed between two metallic conductors. Exposed electrode area: $1 \mathrm{~cm}^{2}$. Frequency range from $10^{4}$ to $10^{-2} \mathrm{~Hz}$.

In the Nyquist plot, it can be noticed a value of $12 \Omega \mathrm{cm}^{2}$ for the impedance of this system. There is not a capacitive behavior in the Nyquist plot. In the Bode plot, a phase angle of 0 degrees was obtained for all the frequency range. In the Bode plot $(\log |\mathrm{Z}|$ vs. frequency), a constant value of $12 \Omega \mathrm{cm}^{2}$ was recorded for the impedance modulus. This horizontal line is characteristic for a non-capacitive behavior. Therefore, this electrical response showed a pure resistive behavior.

In Eq. (2), the term $4 \mathrm{t}_{\mathrm{i}}{ }^{2} \Delta \mathrm{Rf} \mathrm{z}_{\mathrm{th}}(\mathrm{v})$ is associated with the counter-ion diffusion in solid state, since electrons and counter-ions could carry the electrical charge. This phenomenon appears as a $45^{\circ}$ slope straight line in the Nyquist plot, theoretically defined as Warburg impedance. In our case, diffusion processes were not shown in the Nyquist diagram. Taking into account the great size of the counter-ion, $\mathrm{PW}_{12} \mathrm{O}_{40}{ }^{3-}$, the ionic transference number must be very small and the polyoxometalate diffusion will be very prevented inside the polymeric matrix. The counter-ion remains entrapped inside the polymeric matrix and its movement must be very limited.

In this way, equation (2) can be simplified to: 
$\mathrm{Z}_{\mathrm{m} / \mathrm{f} / \mathrm{m}}(\omega)=\mathrm{Rmfe}+\mathrm{Rf}+\mathrm{Rfme}$

This analysis is important from two points of view. On one hand, a first value for the sum of these parameters has been obtained. In the next section, where the whole electrical response will be analyzed (asymmetric configuration metal/PES-PPy-POM fabric/electrolyte), this value will be taken into account to fit the experimental data. On the other hand, results from capacitive elements have not been shown in the Nyquist and Bode plots. For this reason, the equivalent circuit proposed in Fig. 7 can be simplified removing the elements $\mathrm{Cf}$ and $\mathrm{Cmfe}$, capacitive elements from the bulk of the PES-PPyPOM conducting textile and from the metal/PES-PPy-POM textile interface, respectively. Three resistances in series appear now in the electrical circuit: Re, Rf and Rmfe. These resistances are the same defined before. As these relaxations can not be distinguished in the impedance spectra, the sum of these three resistances will be defined as Ren: $\operatorname{Re}+\mathrm{Rf}+\mathrm{Rmfe}$. Taking into account all these comments, a simplified equivalent circuit is proposed in Fig. 10.

\section{Fig. 10. Simplified equivalent circuit for metal/PES-PPy-POM/electrolyte system.}

Before studying the electrochemical behavior of hybrid PES-PPy-POM fabrics in asymmetric configuration, the morphological characteristics of the organic-inorganic PES-PPy-POM textile have been analyzed by SEM obtained by secondary electrons. The SEM micrographs were performed after the different treatments. In Fig. 11-a, it can be observed the SEM micrograph of PES-PPy-POM fabric treated for 1 hour in $\mathrm{pH} 0$ solution. In the micrograph, it could be seen that the layer of polypyrrole coated 
completely the fabric of polyester. The presence of polypyrrole aggregates that could not be removed from the surface of the fabric during the washing stage of the synthesis process was also noticeable. When the samples were soaked for $1 \mathrm{~h}$ in $\mathrm{pH} 7$ and $\mathrm{pH} 13$ solutions, the SEM micrographs did not show any morphological change (Fig. 11-b and $11-c)$.

Fig. 11. SEM micrographs of PES-PPy-POM fabrics treated in different pH solutions: a) pH 0, b) pH 7 and c) pH 13.

\subsubsection{Study of the electrochemical behavior of hybrid PES-PPy-POM fabrics in} asymmetric configuration metal/PES-PPy-POM/electrolyte system

With the purpose of studying the $\mathrm{pH}$ influence on the hybrid organic-inorganic PESPPy-POM fabrics, their electric responses were analyzed in different $\mathrm{pH}$ solutions: $\mathrm{pH}$ 0,7 and 13.

The Nyquist and Bode plots for the samples immersed in different $\mathrm{pH}$ solutions are shown in Figs. 12 and 13. Experimental data were fitted with the equivalent circuit proposed in Fig. 10 and the data obtained are shown in table 1. Electrolyte resistance values were obtained replacing the textile working electrode by a stainless steel one. This measurement was performed for each solution with different $\mathrm{pH}$.

In Figs. 12 and 13, it can be appreciated two characteristic time constants in the Nyquist and Bode plots. The high frequency semicircles in the Nyquist plot represent the relaxation due to the ionic charge transfer at the PES-PPy-POM textile/solution interface corresponding to the counter-ion exchange. If the $\mathrm{pH}$ of the solution increases, the diameter of these semicircles is greater. Relaxations in relation to these processes 
appeared at higher frequencies when the $\mathrm{pH}$ was lower (phase angle vs. frequency plot). Therefore, the counter-ion exchange is faster with lower $\mathrm{pH}$. Table 1 shows that Rfsi is more than an order of magnitude higher at $\mathrm{pH} 13$ than at $\mathrm{pH} 0$. The acidic medium produces the protonation of polypyrrole $[44,45]$ and its oxidation state increases; therefore, more counter-ions are needed to compensate the whole charge of the polymeric chains. This fact would explain the higher ionic exchange as the concentration of $\mathrm{H}^{+}$is higher. The capacitance (Cfsi) shows a slight increase from $\mathrm{pH}$ 13 to $\mathrm{pH}$. This fact could be attributed to a greater conductivity of the protonated polymer due to a higher number of electroactive sites in its structure (polarons, bipolarons and counter-ions), so it would present a higher charge distribution in this interface.

The fitting data in table 1 show that the sum of the ionic and electronic mixed resistance of the PES-PPy-POM textile and the electronic charge transfer resistance between PESPPy-POM textile and the metal tweezers are significantly lower, an order of magnitude, for $\mathrm{pH} 0$ solution (best conductivity) in comparison with the more basic solutions. This conductivity increment for the organic-inorganic conducting textile treated at $\mathrm{pH} 0$ is due to the protonation of polypyrrole in acidic media, as commented before.

Nyquist and Bode plots in Figs. 12 and 13 show a second loop at low frequencies. This second loop is attributed to two overlapped relaxations, the Warburg impedance due to counter-ion diffusion and the ion-electron charge transfer resistance at the PES-PPyPOM textile/solution interface with redox species (Rfsie). In the Bode plot, this second time constant (lower frequency) for the $\mathrm{pH} 0$ solution appears at higher frequencies in comparison with the other more basic solutions. Seeing table 1, values for Warburg impedance and $\mathrm{Rfsie}$ are greater in $\mathrm{pH} 7$ and $\mathrm{pH} 13$ solutions in comparison with $\mathrm{pH} 0$ 
solution. At $\mathrm{pH} 0$, protonated polypyrrole is more oxidized, and repulsion forces between positive charges within the polypyrrole structure swell up the polymer. A more porous structure would allow a better diffusion of the ions. On the other hand, it is important to highlight that the ion-electron charge transfer resistance at the PES-PPyPOM fabric/solution interface with redox species is considerably lower for the organic inorganic PES-PPy-POM textile in pH 0 solution than in the other more basic solutions. Probably an electro-catalytic effect might be expected for the $\mathrm{H}^{+}$reduction for this new electrode material in acidic media. Moreover, counter-ions could also reduce $\mathrm{H}^{+}$to $\mathrm{H}_{2}$. However, the counter-ion used in this work was $\mathrm{PW}_{12} \mathrm{O}_{40}{ }^{3-} \cdot \mathrm{PW}_{12} \mathrm{O}_{40}{ }^{3-}$ is in its higher oxidized state $[46,47]$ and therefore it would not be able to reduce $\mathrm{H}^{+}$to $\mathrm{H}_{2}$. On the other hand, $\mathrm{H}^{+}, \mathrm{HSO}_{4}{ }^{-}$and $\mathrm{SO}_{4}{ }^{2-}$ and $\mathrm{OH}^{-}$are the ions from the electrolyte ( $\mathrm{pH} 0$ sulfuric solution). $\mathrm{OH}^{-}$content was minimum $\left(\approx 10^{-14}\right)$. $\mathrm{HSO}_{4}{ }^{-}$and $\mathrm{SO}_{4}{ }^{2-}$ are inert ions from the point of view of redox reactions. Hereby, the ion-electron charge transfer resistance would be due to the increase of the oxidation state of the PPy polymeric chains that would cause the $\mathrm{H}^{+}$reduction to evolve $\mathrm{H}_{2}$.

Fig. 12. Nyquist plots of PES-PPy-POM fabrics immersed in different pH solutions in asymmetric configuration. Exposed electrode area: $1 \mathrm{~cm}^{2}$. Frequency range from $10^{4}$ to $10^{-2} \mathrm{~Hz}$.

Fig. 13. Bode plots of PES-PPy-POM fabrics immersed in different pH solutions in asymmetric configuration. Exposed electrode area: $1 \mathrm{~cm}^{2}$. Frequency range from $10^{4}$ to $10^{-2} \mathrm{~Hz}$. 


\section{Table 1}

Results of the fitting of impedance data of PES-PPy-POM fabrics in different $p H$ solutions: pH 0 (0.5 $\left.\mathrm{M} \mathrm{H}_{2} \mathrm{SO}_{4}\right)$, pH 7 (phosphates buffer + $\left.0.1 \mathrm{M} \mathrm{Na}_{2} \mathrm{SO}_{4}\right), \mathrm{pH} 13(0.1$ $\left.\mathrm{M} \mathrm{NaOH}+0.1 \mathrm{M} \mathrm{Na}_{2} \mathrm{SO}_{4}\right)$. Resistance units in $\Omega \mathrm{cm}^{2}$ and capacitance units in $\mathrm{F} \mathrm{cm}^{-}$ 2 .

\section{Conclusions}

Dry samples of novel hybrid PES-PPy-POM conducting textiles present electronic conducting properties with semiconducting nature. A value of $44.4 \mathrm{meV}$ was obtained for the activation energy by means of the Arrhenius model.

The electrical response of organic-inorganic PES-PPy-POM conducting textiles immersed in solution has been modeled with a simplified electrical equivalent circuit taking into account the physical-chemical phenomena occurring within this complex system.

EIS analysis showed that the conductivity of the organic-inorganic polypyrrole conducting fabrics increases in more acid solutions due to protonation of polypyrrole. Polypyrrole is protonated and oxidized in acidic solutions and therefore, these hybrid conducting fabrics present higher diffusion of counter-ions due to a more swollen and porous structure. Counter-ion exchange is also higher in more acidic solutions, since a greater number of counter-ions are needed to compensate the charge of more oxidized polypyrrole chains. These novel hybrid organic-inorganic conducting textiles might present in acidic media an electro-catalytic effect for $\mathrm{H}^{+}$reduction reaction to evolve $\mathrm{H}_{2}$. 


\section{Acknowledgements}

Authors thank to the Spanish Ministerio de Ciencia y Tecnología and European Union Funds (FEDER) (CTM2010-18842-C02-02) and Universitat Politècnica de València (Programa de Apoyo a la Investigación y Desarrollo de la UPV (PAID-06-10)) for the financial support. J. Molina is grateful to the Conselleria d'Educació (Generalitat Valenciana) for the FPI fellowship. A.I. del Río is grateful to the Spanish Ministerio de Ciencia y Tecnología for the FPI fellowship.

\section{References}

[1] P. Gómez-Romero, Adv. Mater. 13 (2001) 163-174.

[2] P. Lekpittaya, N. Yanumet, B.P. Grady, E.A. O’Rear, J. Appl. Polym. Sci. 92 (2004) 2629-2636.

[3] D. Kincal, A. Kumar, A. Child, J. Reynolds, Synth. Met. 92 (1998) 53-56.

[4] J. Wu, D. Zhou, C.O. Too, G.G. Wallace, Synth. Met. 155 (2005) 698-701.

[5] K. Wha, H. Jin, S. Hun, J. Appl. Polym. Sci. 88 (2003) 1225-1229.

[6] S. Hun, K. Wha, J. Hyon, J. Appl. Polym. Sci. 91 (2004) 4064-4071.

[7] N.V. Bhat, D.T. Seshadri, M.N. Nate, A.V. Gore, J. Appl. Polym. Sci. 102 (2006) 4690-4695.

[8] E. Hakansson, A. Kaynak, T. Lin, S. Nahavandi, T. Jones, E. Hu, Synth. Met. 144 (2004) 21-28.

[9] J.P. Boutrois, R. Jolly, C. Pétrescu, Synth. Met. 85 (1997) 1405-1406.

[10] H. Kuhn, A. Child, W. Kimbrell, Synth. Met. 71 (1995) 2139-2142. 
[11] D. Akbarov, B. Baymuratov, P. Westbroek, R. Akbarov, K. Declerck, P. Kiekens, J. Appl. Electrochem. 36 (2006) 411-418.

[12] T. Lin, L. Wang, X. Wang, A. Kaynak, Thin Solid Films 479 (2005) 77-82.

[13] F. Ferrero, L. Napoli, C. Tonin, A. Varesano, J. Appl. Polym. Sci. 102 (2006) $4121-4126$.

[14] S. Garg, C. Hurren, A. Kaynak, Synth. Met. 157 (2007) 41-47.

[15] J. Molina, A.I. del Río, J. Bonastre, F. Cases, Eur. Polym. J. 44 (2008) 2087-2098.

[16] H.S. Lee, J. Hong, Synth. Met. 113 (2000) 115-119.

[17] T. Patois, B. Lakard, N. Martin, P. Fievet, Synth. Met. 160 (2010) 2180-2185.

[18] E. Gasana, P. Westbroek, J. Hakuzimana, K. De Clerck, G. Priniotakis, P. Kiekens, D. Tseles, Surf. Coat. Tech. 201 (2006) 3547-3551.

[19] L. Dall'Acqua, C. Tonin, A. Varesano, M. Canetti, W. Porzio, M. Catellani, Synth. Met. 156 (2006) 379-386.

[20] L. Dall'Acqua, C. Tonin, R. Peila, F. Ferrero, M. Catellani, Synth. Met. 146 (2004) 213-221.

[21] K.G. Neoh, T.T. Young, E.T. Kang, K.L. Tan, J. Appl. Polym. Sci. 64 (1997) 519526.

[22] P. Gómez-Romero, J.A. Asensio, S. Borrós, Electrochim. Acta 50 (2005) 47154720.

[23] P. Gómez-Romero, M. Lira-Cantú, Adv. Mater. 9 (1997) 144-147.

[24] K. Bouzek, K.M. Mangold, K. Jüttner, J. Appl. Electrochem. 31 (2001) 501-507.

[25] L. Li, Y. Zhang, J.F. Drillet, R. Dittmeyer, K.M. Jüttner, Chem. Eng. J. 133 (2007) 113-119. 
[26] F.J. Rodríguez, S. Gutiérrez, J.S. Ibanez, J.L. Bravo, N. Batina, Environ. Sci. Technol. 34 (2000) 2018-2023.

[27] Y. Tian, J. Wang, Z. Wang, S. Wang, Synth. Met. 143 (2004) 309-313.

[28] A. Lopes, S. Martins, A. Moraö, M. Magrinho, I. Gonçalves, Port. Electrochim. Acta 22 (2004) 279-294.

[29] A.H. Gemeay, R.G. El-Sharkawy, I.A. Mansour, A.B. Zaki, Appl. Catal. B 80 (2008) 106-115.

[30] A.H. Gemeay, R.G. El-Sharkawy, I.A. Mansour, A.B. Zaki, J. Colloid. Interf. Sci. 308 (2007) 385-394.

[31] Complete textile glossary, available from: http://www.celaneseacetate.com/textile_glossary_filament_acetate.pdf, 2001. Last accessed 23 March 2011.

[32] W. Liang, J. Lei, C.R. Martin, Synth. Met. 52 (1992) 227-239.

[33] W.S. Subrahmanyam, S.K. Das, B.N. Ganguly, A. Bhattacharya, A. De, Mater. Res. Bull. 32 (1997) 1063-1072.

[34] N.V. Blinova, J. Stejskal, M. Trchová, J. Prokes, M. Omastová, Eur. Polym. J. 43 (2007) 2331-2341.

[35] R. Dygas, G. Fafilek, H. Durakpasa, M. W. Breiter, J. Appl. Electrochem. 23 (1993) 553-558.

[36] R. Friend, Nature 441 (2006) 37.

[37] K. Lee, S. Cho, S. H. Park, A. J. Heeger, C.-W. Lee, S.-H. Lee, Nature 441 (2006) $65-68$.

[38] P. Syed Abthagir, R. Saraswathi, Mater. Chem. Phys. 92 (2005) 21-26. 
[39] V. Shaktawat, N. Jain, R. Saxena, N.S. Saxena, K. Sharma, T.P. Sharma, Polym. Bull. 57 (2006) 535-543.

[40] M. Taunk, A. Kapil, S. Chand, J. Mater. Sci: Mater. Electron. 22 (2011) 136-142.

[41] M.A. Vorotyntsev, J.P. Badiali, E. Vieil, Electrochim. Acta 41 (1996) 1375-1381.

[42] T. Van Schaftinghen, C. Deslouis, A. Hubin, H. Terryn, Electrochim. Acta 51 (2006) 1695-1703.

[43] H. Nguyen Thi Le, B. Garcia, C. Deslouis, Q. Le Xuan, Electrochim. Acta 46 (2001) 4259-4272.

[44] M. Krzysztof, Electroanal. 18 (2006) 1537-1551.

[45] J.H. Hwang, M. Pyo, Synth. Met. 157 (2007) 155-159.

[46] W. Feng, T.R. Zhang, Y. Liu, R. Lu, Y.Y. Zhao, J.N. Yao, J. Mater. Sci. 38 (2003) 1045-1048.

[47] S.-X. Guo, A.W.A. Mariotti, C. Schlipf, A.M. Bond, A.G. Wedd, J. Electroanal. Chem. 591 (2006) 7-18. 


\section{Figure Captions}

Fig. 1. Molecular structure of the phosphotungstic acid

Fig. 2. Idealized scheme of the structure of the molecular material formed between polypyrrole and the $\mathrm{PW}_{12} \mathrm{O}_{40}{ }^{3-}$ anion.

Fig. 3. Photograph of GF-1000 sample cell (up to $1000^{\circ} \mathrm{C}$ ): with water recirculation for cooling.

Fig. 4. Scheme of connections for impedance measurements with temperature.

Fig. 5. Bode plots for PES-PPy-POM fabric at different temperatures $\left(25-60{ }^{\circ} \mathrm{C}\right)$. Measurement between two Pt electrodes $\left(0.8 \mathrm{~cm}^{2}\right)$. Frequency range from $10^{4} \mathrm{~Hz}$ to $10^{-2}$ $\mathrm{Hz}$.

Fig. 6. Plot of $\ln (\sigma)$ vs. 1000/T for the data obtained for a PES-PPy-POM fabric.

Fig. 7. Equivalent circuit for metal/PES-PPy-POM/electrolyte system.

Fig. 8. Nyquist plot of a hybrid organic-inorganic PES-PPy-POM fabric placed between two metallic conductors. Exposed electrode area: $1 \mathrm{~cm}^{2}$. Frequency range from $10^{4}$ to $10^{-2} \mathrm{~Hz}$ 
Fig. 9. Bode plots of a hybrid organic-inorganic PES-PPy-POM fabric placed between two metallic conductors. Exposed electrode area: $1 \mathrm{~cm}^{2}$. Frequency range from $10^{4}$ to $10^{-2} \mathrm{~Hz}$

Fig. 10. Simplified equivalent circuit for metal/PES-PPy-POM/electrolyte system.

Fig. 11. SEM micrographs of PES-PPy-POM fabrics treated in different $\mathrm{pH}$ solutions: a) $\mathrm{pH}$ 0, b) pH 7 and, c) pH 13.

Fig. 12. Nyquist plots of PES-PPy-POM fabrics immersed in different $\mathrm{pH}$ solutions in asymmetric configuration. Exposed electrode area: $1 \mathrm{~cm}^{2}$. Frequency range from $10^{4}$ to $10^{-2} \mathrm{~Hz}$

Fig. 13. Bode plots of PES-PPy-POM fabrics immersed in different $\mathrm{pH}$ solutions in asymmetric configuration. Exposed electrode area: $1 \mathrm{~cm}^{2}$. Frequency range from $10^{4}$ to $10^{-2} \mathrm{~Hz}$ 


\section{Table Captions}

Table 1

Results of the fitting of impedance data of PES-PPy-POM fabrics in different $\mathrm{pH}$ solutions: $\mathrm{pH} 0\left(0.5 \mathrm{M} \mathrm{H}_{2} \mathrm{SO}_{4}\right), \mathrm{pH} 7$ (phosphates buffer $\left.+0.1 \mathrm{M} \mathrm{Na}_{2} \mathrm{SO}_{4}\right), \mathrm{pH} 13(0.1$ $\mathrm{M} \mathrm{NaOH}+0.1 \mathrm{M} \mathrm{Na}_{2} \mathrm{SO}_{4}$ ). Resistance units in $\Omega \mathrm{cm}^{2}$ and capacitance units in $\mathrm{F} \mathrm{cm}^{-2}$. 


\title{
Study of the electrical properties of novel hybrid organic-inorganic conducting textiles of polypyrrole-phosphotungstate-polyester using Electrochemical
} Impedance Spectroscopy

\author{
J. Bonastre ${ }^{\mathrm{a}}$, J. Molina ${ }^{\mathrm{a}}$, A.I. del Río ${ }^{\mathrm{a}}$, J.C. Galván ${ }^{\mathrm{b}}$, F. Cases ${ }^{\mathrm{a}, *}$ \\ ${ }^{a}$ Departamento de Ingeniería Textil y Papelera, EPS de Alcoy, Universitat Politècnica \\ de València, Plaza Ferrándiz y Carbonell s/n, 03801 Alcoy, Spain \\ ${ }^{b}$ Centro Nacional de Investigaciones Metalúrgicas, CSIC \\ Avda. Gregorio del Amo 8, 28040 Madrid, Spain
}

\begin{abstract}
The electrical properties of novel hybrid organic-inorganic conducting fabrics of polyester (PES) coated with polypyrrole- $\mathrm{PW}_{12} \mathrm{O}_{40}{ }^{3-}$ (PPy-POM) have been tested for dry samples and specimens immersed in different $\mathrm{pH}$ solutions $(1,7,13)$. Electrical properties changes were measured by means of Electrochemical Impedance Spectroscopy (EIS). This study showed that organic-inorganic PES-PPy-POM conducting textiles act as electronic conductors with semiconducting nature. The electrical conductivity was measured for different temperatures and a value of $44.4 \mathrm{meV}$ was obtained for the activation energy by means of Arrhenius model. Samples immersed in solution increased their conductivity in more acid solutions due to polypyrrole protonation. As acidity increased protonation and oxidation state of polypyrrole chains, a greater diffusion of counter-ions was observed since the hybrid conducting textiles presented a more swollen and porous structure. Counter-ion
\end{abstract}


exchange was higher in more acid solutions since more charge was needed to compensate the positive charge of more oxidized polypyrrole chains. A catalytic effect might be expected for the $\mathrm{H}^{+}$reduction for this new organic-inorganic electrode material in acid media.

Keywords: Conducting fabrics, organic-inorganic, polypyrrole, phosphotungstate, EIS.

* Corresponding author. Tel.: +34 9665284 12; fax: +34 966528438 .

E-mail address: fjcases@txp.upv.es (Prof. F. Cases).

\section{Introduction}

Conducting polymers as polypyrrole have been studied during the last three decades due to their promising properties as revolutionary materials [1]. One very interesting application of conducting polymers is conducting textiles. Different methods have been employed to produce conducting textiles, such as the synthesis of conducting polymers on the fabrics [2-10], the chemical metallization of fibers [11], etc. Applications of conducting textiles are varied and numerous; such as: antistatic materials [2], gas sensors [3], biomechanical sensors [4], electrotherapy [5, 6], heating devices [7-9] or microwave attenuation [10].

During the formation of polypyrrole, positive charges are created in the polypyrrole structure. Negative charges provided by a counter-ion compensate the positive charges to maintain the electroneutrality principle. If the counter-ion is expelled from the structure (dedoping), there is a great loss of its electrical properties. Low size anions 
such as $\mathrm{Cl}^{-}$have been employed as counter-ions, but their stability is low [10]. To prevent this phenomenon, bulky anions with high molecular size have been employed in bibliography. Typical counter-ions employed in the production of polypyrrole-based conducting fabrics are organic molecules with high size; such as: anthraquinone sulfonic acid (AQSA) [3, 8, 10, 12-15], dodecylbenzene sulfonic acid (DBSA) [2, 13], p-toluene sulfonic acid (PTSA) [3, 10, 13, 16, 17], naphthalenedisulfonic acid (NDSA) $[4,10,13]$, benzenesulfonic acid (BSA) [5, 18], naphthalenesulfonic acid (NSA) [10, $16,17]$ and anthraquinone disulfonic acid (AQDSA) $[19,20]$. If the size of the counterion is high, its diffusion is prevented and it remains in the polypyrrole structure [21]. Polyoxometalates, POMs, are also anions of high volume and charge and present electrochemical activity and catalytic properties. POMs are oxide clusters whose size and solubility have caused them to be traditionally considered within the framework of molecular chemistry. They are indeed complex molecules with several metallic ions coordinated by shared oxide ions, forming a highly symmetrical metal oxide cluster [1]. Phosphotungstic acid, $\mathrm{H}_{3} \mathrm{PW}_{12} \mathrm{O}_{40}(\mathrm{POM})$, has been used in this work as a counter-ion to be immobilized within the polymeric matrix. The molecular structure of phosphotungstic acid is shown in Fig. 1 [22].

\section{Fig. 1. Molecular structure of phosphotungstic acid}

In addition, POMs present the possibility to produce a hybrid material when combined with conducting polymers such as polypyrrole. Therefore, a hybrid material with combined properties (organic-inorganic) is synthesized. The molecular material formed between polypyrrole and the phosphotungstate anion is showed in Fig. 2 [23]. 
Fig. 2. Idealized scheme of the structure of the molecular material formed between polypyrrole and $\mathrm{PW}_{12} \mathrm{O}_{40}{ }^{3-}$ anion.

One of the applications that our group is investigating is the employment of organicinorganic PPy-POM conducting fabrics in catalysis; or as a support with high surface area to electrodeposit Pt nanoparticles and enhance its electroactivity [24, 25]. The employment of conducting polymers in environmental purposes has been reported [2630]. For instance, electrodes modified with conducting polymers have been used in $\mathrm{Cr}^{6+}$ (toxic) reduction to $\mathrm{Cr}^{3+}$ (not toxic) [26] or nitrites electroreduction [27]. Polypyrrole coated fabrics have been employed in the electrochemical removal of the textile dye $\mathrm{C}$. I. Direct Red 80 [28]. Polyaniline/ $\mathrm{MnO}_{2}$ catalyst has been employed in the degradation of organic dyes such as Direct Red 81, Indigo Carmine and Acid Blue 92 [29, 30].

For this purpose, the objective of this work is to study the electrical properties of novel hybrid organic-inorganic PES-PPy-POM conducting textiles using EIS to measure dry samples and also immersed in different $\mathrm{pH}$ solutions. This is essential to optimize the operational $\mathrm{pH}$ range for its employment in wastewater treatment.

\section{Experimental}

\subsection{Reagents and materials}

Analytical grade pyrrole, ferric chloride, sulfuric acid, sodium sulfate, sodium hydroxide, sodium dihydrogenophosphate and disodium hydrogenophosphate were purchased from Merck. Normapur acetone was from Prolabo. Analytical grade 
phosphotungstic acid hydrate was supplied by Fluka. When needed, solutions were deoxygenated by bubbling nitrogen $\left(\mathrm{N}_{2}\right.$ premier X50S). Ultrapure water was obtained from an Elix 3 Millipore-Milli-Q Advantage A10 system with a resistivity near to 18.2 $\mathrm{M} \Omega \mathrm{cm}$.

Polyester textile was acquired from Viatex S. A. and its characteristics were: fabric surface density, $140 \mathrm{~g} \mathrm{~m}^{-2}$; warp threads per cm, 20 (warp linear density, $167 \mathrm{dtex}$ ); weft threads per cm, 60 (weft linear density, 500 dtex). These are specific terms used in the field of textile industry and their meaning can be consulted in a textile glossary [31].

\subsection{Chemical synthesis of PES-PPy-POM}

Chemical synthesis of organic-inorganic PPy-POM on polyester textiles was done as reported in our previous study [15]. The size of the samples was $6 \mathrm{~cm} \times 6 \mathrm{~cm}$ approximately. Previously to reaction, polyester was degreased with acetone in ultrasound bath and washed with water. Pyrrole concentration employed was $2 \mathrm{~g} \mathrm{~L}^{-1}$ and the molar ratios of reagents employed in the chemical synthesis bath were pyrrole: $\mathrm{FeCl}_{3}$ : POM (1: 2.5: 0.2). The next stage was the adsorption of pyrrole and counter-ion $(\mathrm{POM})(\mathrm{V}=200 \mathrm{ml})$ on the fabric for $30 \mathrm{~min}$. At the end of this time, the $\mathrm{FeCl}_{3}$ solution $(\mathrm{V}=50 \mathrm{ml})$ was added and oxidation of the monomer took place during $150 \mathrm{~min}$. Adsorption and reaction took place in a precipitation beaker and in an ice bath without stirring. The reason for carrying out the synthesis at low temperatures is that the polymer obtained presents better properties at lower temperatures. Polypyrrole synthesized at lower temperature exhibits longer conjugation length, fewer structural defects, higher doping level [32] and consequently, higher conductivity [32, 33]. Higher temperatures increase the reaction rate, more oligomers are formed per unit of time and 
the transport is not effective onto fiber surface [12]. When this happens, polypyrrole particles are formed in solution. Decreasing the temperature of the solution, the formation of polypyrrole particles in solution is lowered. The temperature when the oxidant is added varies since pyrrole polymerization begins. As this is an exothermal reaction and heat is generated, the temperature of the synthesis solutions rises [34]. The ice bath minimizes significant temperature changes. The conducting fabric was washed with water to remove PPy not joined to fibers. The conducting textile was dried in a desiccator for at least $24 \mathrm{~h}$ before measurements. The weight increase was measured obtaining a value between $7-10 \%$.

\subsection{Electrochemical Impedance Spectroscopy characterization with temperature}

EIS measurements were employed to obtain the conductivity of the PES-PPy-POM sample. An electrochemical interface Solartron 1286 was employed to control the potential and a Solartron 1253 Gain-Phase analyzer was employed to perform EIS measurements in the $10^{4}$ to $10^{-2} \mathrm{~Hz}$ frequency range. The amplitude of the sinusoidal voltage employed was $\pm 10 \mathrm{mV}$. Each measurement was carried out at a constant imposed potential equal to the stabilized open circuit potential at the beginning of the experiment. EIS measurements were also carried out at different temperatures (25-60 $\left.{ }^{\circ} \mathrm{C}\right)$. The impedance measurements were carried out using a 2-probe setup in a GF-1000 sample cell supplied by Equipos Instrumentación y Control S.L. (EIC). Fig. 3 shows the GF-1000 sample cell employed. A furnace Carbolite CTF 12/65/550 with a Eurotherm 2408 temperature controller was employed to control the temperature with the Settemp 3.0 software (developed by EIC). A scheme of connections for impedance measurements with temperature is shown in Fig. 4 [35]. To analyze quantitatively the 
electrochemical behavior of the samples, the experimental impedance data were modeled and fitted to data generated by using suitable electrical equivalent circuits and a non-linear least squares fitting minimization method; included in the ZPlot/ZView software (3.1c version) from Scribner Associates Inc, Southern Pines, NC, USA.

Fig. 3. Photograph of GF-1000 sample cell (up to $1000^{\circ} \mathrm{C}$ ): with water recirculation for cooling.

Fig. 4. Scheme of connections for impedance measurements with temperature.

\subsection{EIS study of organic-inorganic PES-PPy-POM fabrics in different $p H$ solutions}

Different samples of PES-PPy-POM $(2 \mathrm{~cm} \times 2 \mathrm{~cm})$ were analyzed in different $\mathrm{pH}$ solutions. The solutions employed were: $0.5 \mathrm{M} \mathrm{H}_{2} \mathrm{SO}_{4}(\mathrm{pH} \sim 0)$, phosphates buffer +0.1 $\mathrm{M} \mathrm{Na}_{2} \mathrm{SO}_{4}(\mathrm{pH} \sim 7)$ and $0.1 \mathrm{M} \mathrm{NaOH}+0.1 \mathrm{M} \mathrm{Na}_{2} \mathrm{SO}_{4}(\mathrm{pH} \sim 13)$. After $1 \mathrm{~h}$ of contact with the different $\mathrm{pH}$ solutions, the samples were analyzed by means of EIS.

The EIS measurements were performed in the same frequency range and amplitude than in Section 2.3. The experimental results were also analyzed as in Section 2.3.

The EIS analyses for metal/PES-PPy-POM fabric/metal symmetrical configuration were measured placing a drop of mercury on a hybrid PES-PPy-POM conducting fabric placed on a stainless steel plate. The electric contact was done with a stainless steel rod contacting with the drop of mercury employing a two-electrode configuration. These measurements were performed for samples treated in $\mathrm{pH} 0$ solution in order to obtain preliminary data for fitting experimental data in asymmetrical configuration. A standard three-electrode design was employed for the asymmetrical configuration metal/PESPPy-POM/electrolyte system. In this configuration the working electrode was the 
conducting fabric placed on a stainless steel plate; the counter electrode was a stainless steel rod, and the reference electrode was an $\mathrm{Ag} / \mathrm{AgCl}(3 \mathrm{M} \mathrm{KCl})$. The electrolyte resistance data were obtained removing the textile working electrode and putting only the stainless electrode for each different $\mathrm{pH}$ solution.

\subsection{SEM characterization}

A Jeol JSM-6300 Scanning Electron Microscope was employed to observe the morphology of the samples. SEM analyses were performed using an acceleration voltage of $20 \mathrm{kV}$.

\section{Results and discussion}

\subsection{Electrochemical Impedance Spectroscopy characterization with temperature}

The EIS measurements were conducted with a temperature cell GF-1000. The sample was placed between two Pt plates of $0.8 \mathrm{~cm}^{2}$. In Fig. 5, the Bode plots for the sample of PES-PPy-POM measured at different temperatures $\left(25-60{ }^{\circ} \mathrm{C}\right)$ are shown. In the upper diagram it can be seen the impedance modulus $(|Z|)$ at the different frequencies. The impedance modulus gives us the resistance of the conducting fabric at the different frequencies and temperatures employed. It can be seen that as the temperature increases, the impedance modulus lowers. The equivalent circuit employed to adjust the data values was a single resistance $(\mathrm{R})$. The data were adjusted with the Zview software and the resistance of the sample at the different temperatures was obtained. These values were employed to obtain the electrical conductivity $\left(\mathrm{S} \mathrm{cm}^{-1}\right)$. 
The second diagram in Fig. 5 shows the data for the phase angle at different frequencies for the same samples of the first diagram. The sample of PES-PPy-POM showed $0^{\circ}$ for the phase angle at all the temperatures employed. This value of phase angle indicates that the material acts as a resistor with different resistances as it was shown in the first Bode plot. The phase angle for insulating materials is $90^{\circ}$, so the fabric acts as an electronic conductor.

Fig. 5. Bode plots for the PES-PPy-POM fabric at different temperatures $\left(25-60{ }^{\circ} \mathrm{C}\right)$. Measurement between two Pt electrodes $\left(0.8 \mathrm{~cm}^{2}\right)$. Frequency range from $10^{4} \mathrm{~Hz}$ to $10^{-2} \mathrm{~Hz}$

\subsubsection{Adjust to the Arrhenius model}

The electrical conductivity $\left(\mathrm{S} \mathrm{cm}^{-1}\right)$ of the samples at the different temperatures was calculated with the data of resistance, thickness of the sample $(0.017 \mathrm{~cm})$ and measured area $\left(0.8 \mathrm{~cm}^{2}\right)$. The electrical conductivity of conducting fabric of PES-PPy-POM increases with temperature as it was commented before, this indicates a semiconducting nature. This type of behavior is the typical of conducting polymers, as thermal excitation is needed to move charge carriers [36]. The opposite behavior (metallic conduction) only has been reported in ordered polyaniline for conducting polymers [37]. The electrical conductivity behavior with temperature can be explained using different models. In this section we have applied the Arrhenius model (equation 1) [3840].

$\sigma=\sigma_{0} \exp \left[-\frac{E_{a}}{k T}\right](1)$ 
Where $\sigma$ is the conductivity $\left(\mathrm{S} \mathrm{cm}^{-1}\right)$ at each temperature, $\sigma_{0}$ is the conductivity at room temperature, $\mathrm{E}_{\mathrm{a}}(\mathrm{eV})$ is the carrier activation energy and $\mathrm{k}$ is the Boltzmann constant $\left(8.61734 \cdot 10^{5} \mathrm{eV} \mathrm{K}^{-1}\right)$. The plot of $\ln (\sigma)$ vs $1000 / \mathrm{T}$ is shown in Fig. 6. As it was explained, the conductivity increased with the increase of temperature. The data from 25 to $60{ }^{\circ} \mathrm{C}$ gives a straight line, so the data adjust to the Arrhenius model. The slope of the adjust is equal to $E_{a} / 1000 \mathrm{k}$, so the activation energy can be calculated from the value of the slope obtained by the linear adjust. The activation energy obtained was $44.4 \mathrm{meV}$. Similar values of activation energies have been obtained in bibliography for polypyrrole $[39,40]$.

Fig. 6. Plot of $\ln (\sigma)$ vs. 1000/T for the data obtained for a PES-PPy-POM fabric.

\subsection{EIS study of organic-inorganic PES-PPy-POM fabrics in different $p H$ solutions}

For an electroactive conducting polymer (deposited on PES; that is an electrical insulating material); in solution the following contributions can be expected to its impedance:

- An electronic charge transfer resistance between the PES-PPy-POM conducting textile and the metal tweezers.

- Charge transport within the PES-PPy-POM conducting textile: electrons, polarons, bipolarons, anions and cations. The charge transport is carried out by a coupled electron-ion transport inside the film [41].

- The ionic charge transfer resistance between the PES-PPy-POM conducting textile and the solution. 
- An ion-electron charge transfer resistance between the PES-PPy-POM conducting textile and the solution. Generally, the polymer/solution interface is an electron blocking surface when no-redox couples are in solution [42]. Nevertheless, in this work, solutions with high $\mathrm{H}^{+}$or $\mathrm{OH}^{-}$concentrations have been used. Hereby, this ion-electron charge transfer could appear and it must be taken into account.

The electrical phenomena commented previously can be modeled taking into account the equivalent circuits proposed by Nguyen Thi Le et al. and Van Schaftinghen et al. $[42,43]$. The proposed equivalent circuit is shown in Fig. 7, where the different elements have the following meanings:

Fig. 7. Equivalent circuit for metal/PES-PPy-POM/electrolyte system.

- Re: Electrolyte resistance

- Rfsi: Ionic charge transfer resistance at the PES-PPy-POM textile/solution interface corresponding to the counter-ion exchange. Cfsi: Space charge capacitance at the PESPPy-POM textile/solution interface corresponding to the counter-ion exchange.

- W: Warburg impedance due to counter-ion diffusion. W-R: Diffusion resistance. W-T: $1^{2} / \mathrm{D}(\mathrm{s}), \mathrm{l}$ : length of the diffusion layer, D: binary electron-ion diffusion coefficient. WP: Warburg exponent.

- Rfsie: Ion-electron charge transfer resistance at the PES-PPy-POM textile/solution interface with redox species.

- Rfeon: Electronic resistance of the PES-PPy-POM textile. 
- Rfion: Ionic resistance of the PES-PPy-POM textile. Cf: Capacitance in parallel associated with Rfeon and Rfion to account for dielectric properties of the PES-PPyPOM textile.

- Rmfe: Electronic charge transfer resistance corresponding to the electron exchange between the PES-PPy-POM textile and the metal tweezers. Cmfe: Space charge capacitance corresponding to the electron exchange at the metal/PES-PPy-POM textile interface.

- Rmeon: Electronic resistance of the metallic tweezers. This metal bulk resistance is near to 0 for metals.

Normally, different electrical phenomena can not be understood directly in the electrical response plotted in the Nyquist and Bode plots. Sometimes, the terms associated with the metal/sample interface and the sample/solution one are interchangeable, which makes it impossible to unambiguously attribute the respective relaxations [42]. Therefore, before measuring the electrical response for the asymmetrical configuration metal/PES-PPy-POM textile/electrolyte, the electrical response of the organic-inorganic PES-PPy-POM textile treated in $\mathrm{pH} 0$ solution was measured. A drop of mercury was placed on the hybrid PES-PPy-POM fabric which was located on a stainless steel plate employing a two-electrode configuration. These measurements were performed for samples treated in $\mathrm{pH} 0$ solution with the purpose of obtaining preliminary data for fitting experimental data in asymmetric configuration. Moreover, this symmetrical configuration metal/PES-PPy-POM textile/metal was carried out in order to understand the relaxations due to electronic and ionic resistances (ionic and electronic mixed conductivity), electronic charge transfer between metal and polymer, and ionic diffusion 
within the hybrid conducting textile, since ion-electron charge transfer from electrolyte is blocked in this system.

3.2.1. Study of the electrochemical behavior of hybrid organic-inorganic PES-PPyPOM fabrics between two metallic conductors

The impedance response for metal/PES-PPy-POM textile/metal symmetrical configuration could be defined by the following relationship proposed by Vorotyntsev et al. [41]:

$$
\begin{aligned}
& Z_{\mathrm{m} / \mathrm{f} / \mathrm{m}}(\omega)=\mathrm{Rmfe}+\mathrm{Rf}+\mathrm{Rfme}+4 \mathrm{t}_{\mathrm{i}}^{2} \Delta \mathrm{Rf}_{\mathrm{th}}(v) \\
& \mathrm{Z}_{\mathrm{th}}(v)=v^{-1} \tanh v, \Delta \mathrm{Rf}=\mathrm{L}(4 \mathrm{DC} \rho)^{-1} \\
& v=\left(\mathrm{j} \omega \mathrm{L}^{2} / 4 \mathrm{D}\right)^{1 / 2}
\end{aligned}
$$

where Rmfe and Rfme: electronic interfacial charge transfer resistances between the metallic tweezers and PES-PPy-POM fabric, Rf: high-frequency bulk-film resistance $\left(\right.$ Rfeon + Rfion), $t_{\mathrm{i}}$ : ionic migration (high-frequency) transference number, L: film thickness, D: binary electron-ion diffusion coefficient, $\mathrm{C} \rho$ : redox capacitance per unit volume, $\omega$ : angular frequency. The last term of the first equation (2) is due to the counter-ion diffusive component in the bulk of the conducting polymer. The organicinorganic PES-PPy-POM fabric treated with $\mathrm{pH} 0$ sulfuric acid solution was placed between two metallic conductors and the EIS measurements were begun with a twoelectrode system. Figs. 8 and 9 show the Nyquist and Bode plots for this system. 
Fig. 8. Nyquist plot of a hybrid organic-inorganic PES-PPy-POM fabric placed between two metallic conductors. Exposed electrode area: $1 \mathrm{~cm}^{2}$. Frequency range from $10^{4}$ to $10^{-2} \mathrm{~Hz}$.

Fig. 9. Bode plots of a hybrid organic-inorganic PES-PPy-POM fabric placed between two metallic conductors. Exposed electrode area: $1 \mathrm{~cm}^{2}$. Frequency range from $10^{4}$ to $10^{-2} \mathrm{~Hz}$

In the Nyquist plot, it can be noticed a value of $12 \Omega \mathrm{cm}^{2}$ for the impedance of this system. There is not a capacitive behavior in the Nyquist plot. In the Bode plot, a phase angle of 0 degrees was obtained for all the frequency range. In the Bode plot $(\log |\mathrm{Z}|$ vs. frequency), a constant value of $12 \Omega \mathrm{cm}^{2}$ was recorded for the impedance modulus. This horizontal line is characteristic for a non-capacitive behavior. Therefore, this electrical response showed a pure resistive behavior.

In Eq. (2), the term $4 \mathrm{t}_{\mathrm{i}}{ }^{2} \Delta \mathrm{Rf} \mathrm{z}_{\mathrm{th}}(\mathrm{v})$ is associated with the counter-ion diffusion in solid state, since electrons and counter-ions could carry the electrical charge. This phenomenon appears as a $45^{\circ}$ slope straight line in the Nyquist plot, theoretically defined as Warburg impedance. In our case, diffusion processes were not shown in the Nyquist diagram. Taking into account the great size of the counter-ion, $\mathrm{PW}_{12} \mathrm{O}_{40}{ }^{3-}$, the ionic transference number must be very small and the polyoxometalate diffusion will be very prevented inside the polymeric matrix. The counter-ion remains entrapped inside the polymeric matrix and its movement must be very limited.

In this way, equation (2) can be simplified to: 
$\mathrm{Z}_{\mathrm{m} / \mathrm{f} / \mathrm{m}}(\omega)=\mathrm{Rmfe}+\mathrm{Rf}+\mathrm{Rfme}$

This analysis is important from two points of view. On one hand, a first value for the sum of these parameters has been obtained. In the next section, where the whole electrical response will be analyzed (asymmetric configuration metal/PES-PPy-POM fabric/electrolyte), this value will be taken into account to fit the experimental data. On the other hand, results from capacitive elements have not been shown in the Nyquist and Bode plots. For this reason, the equivalent circuit proposed in Fig. 7 can be simplified removing the elements $\mathrm{Cf}$ and Cmfe, capacitive elements from the bulk of the PES-PPyPOM conducting textile and from the metal/PES-PPy-POM textile interface, respectively. Three resistances in series appear now in the electrical circuit: $\mathrm{Re}, \mathrm{Rf}$ and Rmfe. These resistances are the same defined before. As these relaxations can not be distinguished in the impedance spectra, the sum of these three resistances will be defined as Ren: $\operatorname{Re}+\mathrm{Rf}+\mathrm{Rmfe}$. Taking into account all these comments, a simplified equivalent circuit is proposed in Fig. 10.

Fig. 10. Simplified equivalent circuit for metal/PES-PPy-POM/electrolyte system.

Before studying the electrochemical behavior of hybrid PES-PPy-POM fabrics in asymmetric configuration, the morphological characteristics of the organic-inorganic PES-PPy-POM textile have been analyzed by SEM obtained by secondary electrons. The SEM micrographs were performed after the different treatments. In Fig. 11-a, it can be observed the SEM micrograph of PES-PPy-POM fabric treated for 1 hour in $\mathrm{pH} 0$ solution. In the micrograph, it could be seen that the layer of polypyrrole coated 
completely the fabric of polyester. The presence of polypyrrole aggregates that could not be removed from the surface of the fabric during the washing stage of the synthesis process was also noticeable. When the samples were soaked for $1 \mathrm{~h}$ in $\mathrm{pH} 7$ and $\mathrm{pH} 13$ solutions, the SEM micrographs did not show any morphological change (Fig. 11-b and $11-c)$.

Fig. 11. SEM micrographs of PES-PPy-POM fabrics treated in different pH solutions: a) pH 0, b) pH 7 and c) pH 13.

3.2.2. Study of the electrochemical behavior of hybrid PES-PPy-POM fabrics in asymmetric configuration metal/PES-PPy-POM/electrolyte system

With the purpose of studying the $\mathrm{pH}$ influence on the hybrid organic-inorganic PESPPy-POM fabrics, their electric responses were analyzed in different $\mathrm{pH}$ solutions: $\mathrm{pH}$ 0,7 and 13.

The Nyquist and Bode plots for the samples immersed in different $\mathrm{pH}$ solutions are shown in Figs. 12 and 13. Experimental data were fitted with the equivalent circuit proposed in Fig. 10 and the data obtained are shown in table 1. Electrolyte resistance values were obtained replacing the textile working electrode by a stainless steel one. This measurement was performed for each solution with different $\mathrm{pH}$.

In Figs. 12 and 13, it can be appreciated two characteristic time constants in the Nyquist and Bode plots. The high frequency semicircles in the Nyquist plot represent the relaxation due to the ionic charge transfer at the PES-PPy-POM textile/solution interface corresponding to the counter-ion exchange. If the $\mathrm{pH}$ of the solution increases, the diameter of these semicircles is greater. Relaxations in relation to these processes 
appeared at higher frequencies when the $\mathrm{pH}$ was lower (phase angle vs. frequency plot). Therefore, the counter-ion exchange is faster with lower $\mathrm{pH}$. Table 1 shows that Rfsi is more than an order of magnitude higher at $\mathrm{pH} 13$ than at $\mathrm{pH}$. The acidic medium produces the protonation of polypyrrole $[44,45]$ and its oxidation state increases; therefore, more counter-ions are needed to compensate the whole charge of the polymeric chains. This fact would explain the higher ionic exchange as the concentration of $\mathrm{H}^{+}$is higher. The capacitance (Cfsi) shows a slight increase from $\mathrm{pH}$ 13 to $\mathrm{pH}$. This fact could be attributed to a greater conductivity of the protonated polymer due to a higher number of electroactive sites in its structure (polarons, bipolarons and counter-ions), so it would present a higher charge distribution in this interface.

The fitting data in table 1 show that the sum of the ionic and electronic mixed resistance of the PES-PPy-POM textile and the electronic charge transfer resistance between PESPPy-POM textile and the metal tweezers are significantly lower, an order of magnitude, for $\mathrm{pH} 0$ solution (best conductivity) in comparison with the more basic solutions. This conductivity increment for the organic-inorganic conducting textile treated at $\mathrm{pH} 0$ is due to the protonation of polypyrrole in acidic media, as commented before.

Nyquist and Bode plots in Figs. 12 and 13 show a second loop at low frequencies. This second loop is attributed to two overlapped relaxations, the Warburg impedance due to counter-ion diffusion and the ion-electron charge transfer resistance at the PES-PPyPOM textile/solution interface with redox species (Rfsie). In the Bode plot, this second time constant (lower frequency) for the $\mathrm{pH} 0$ solution appears at higher frequencies in comparison with the other more basic solutions. Seeing table 1, values for Warburg impedance and $\mathrm{Rfsie}$ are greater in $\mathrm{pH} 7$ and $\mathrm{pH} 13$ solutions in comparison with $\mathrm{pH} 0$ 
solution. At $\mathrm{pH} 0$, protonated polypyrrole is more oxidized, and repulsion forces between positive charges within the polypyrrole structure swell up the polymer. A more porous structure would allow a better diffusion of the ions. On the other hand, it is important to highlight that the ion-electron charge transfer resistance at the PES-PPyPOM fabric/solution interface with redox species is considerably lower for the organic inorganic PES-PPy-POM textile in $\mathrm{pH} 0$ solution than in the other more basic solutions. Probably an electro-catalytic effect might be expected for the $\mathrm{H}^{+}$reduction for this new electrode material in acidic media. Moreover, counter-ions could also reduce $\mathrm{H}^{+}$to $\mathrm{H}_{2}$. However, the counter-ion used in this work was $\mathrm{PW}_{12} \mathrm{O}_{40}{ }^{3-} \cdot \mathrm{PW}_{12} \mathrm{O}_{40}{ }^{3-}$ is in its higher oxidized state $[46,47]$ and therefore it would not be able to reduce $\mathrm{H}^{+}$to $\mathrm{H}_{2}$. On the other hand, $\mathrm{H}^{+}, \mathrm{HSO}_{4}{ }^{-}$and $\mathrm{SO}_{4}{ }^{2-}$ and $\mathrm{OH}^{-}$are the ions from the electrolyte ( $\mathrm{pH} 0$ sulfuric solution). $\mathrm{OH}^{-}$content was minimum $\left(\approx 10^{-14}\right)$. $\mathrm{HSO}_{4}{ }^{-}$and $\mathrm{SO}_{4}{ }^{2-}$ are inert ions from the point of view of redox reactions. Hereby, the ion-electron charge transfer resistance would be due to the increase of the oxidation state of the PPy polymeric chains that would cause the $\mathrm{H}^{+}$reduction to evolve $\mathrm{H}_{2}$.

Fig. 12. Nyquist plots of PES-PPy-POM fabrics immersed in different pH solutions in asymmetric configuration. Exposed electrode area: $1 \mathrm{~cm}^{2}$. Frequency range from $10^{4}$ to $10^{-2} \mathrm{~Hz}$.

Fig. 13. Bode plots of PES-PPy-POM fabrics immersed in different pH solutions in asymmetric configuration. Exposed electrode area: $1 \mathrm{~cm}^{2}$. Frequency range from $10^{4}$ to $10^{-2} \mathrm{~Hz}$. 


\section{Table 1}

Results of the fitting of impedance data of PES-PPy-POM fabrics in different $p H$ solutions: pH 0 (0.5 $\left.\mathrm{M} \mathrm{H}_{2} \mathrm{SO}_{4}\right), p H 7$ (phosphates buffer + $\left.0.1 \mathrm{M} \mathrm{Na}_{2} \mathrm{SO}_{4}\right)$, pH $13(0.1$ $\left.\mathrm{M} \mathrm{NaOH}+0.1 \mathrm{M} \mathrm{Na}_{2} \mathrm{SO}_{4}\right)$. Resistance units in $\Omega \mathrm{cm}^{2}$ and capacitance units in $\mathrm{F} \mathrm{cm}^{-}$ 2 .

\section{Conclusions}

Dry samples of novel hybrid PES-PPy-POM conducting textiles present electronic conducting properties with semiconducting nature. A value of $44.4 \mathrm{meV}$ was obtained for the activation energy by means of the Arrhenius model.

The electrical response of organic-inorganic PES-PPy-POM conducting textiles immersed in solution has been modeled with a simplified electrical equivalent circuit taking into account the physical-chemical phenomena occurring within this complex system.

EIS analysis showed that the conductivity of the organic-inorganic polypyrrole conducting fabrics increases in more acid solutions due to protonation of polypyrrole. Polypyrrole is protonated and oxidized in acidic solutions and therefore, these hybrid conducting fabrics present higher diffusion of counter-ions due to a more swollen and porous structure. Counter-ion exchange is also higher in more acidic solutions, since a greater number of counter-ions are needed to compensate the charge of more oxidized polypyrrole chains. These novel hybrid organic-inorganic conducting textiles might present in acidic media an electro-catalytic effect for $\mathrm{H}^{+}$reduction reaction to evolve $\mathrm{H}_{2}$. 


\section{Acknowledgements}

Authors thank to the Spanish Ministerio de Ciencia y Tecnología and European Union Funds (FEDER) (CTM2010-18842-C02-02) and Universitat Politècnica de València (Programa de Apoyo a la Investigación y Desarrollo de la UPV (PAID-06-10)) for the financial support. J. Molina is grateful to the Conselleria d'Educació (Generalitat Valenciana) for the FPI fellowship. A.I. del Río is grateful to the Spanish Ministerio de Ciencia y Tecnología for the FPI fellowship.

\section{References}

[1] P. Gómez-Romero, Adv. Mater. 13 (2001) 163-174.

[2] P. Lekpittaya, N. Yanumet, B.P. Grady, E.A. O’Rear, J. Appl. Polym. Sci. 92 (2004) 2629-2636.

[3] D. Kincal, A. Kumar, A. Child, J. Reynolds, Synth. Met. 92 (1998) 53-56.

[4] J. Wu, D. Zhou, C.O. Too, G.G. Wallace, Synth. Met. 155 (2005) 698-701.

[5] K. Wha, H. Jin, S. Hun, J. Appl. Polym. Sci. 88 (2003) 1225-1229.

[6] S. Hun, K. Wha, J. Hyon, J. Appl. Polym. Sci. 91 (2004) 4064-4071.

[7] N.V. Bhat, D.T. Seshadri, M.N. Nate, A.V. Gore, J. Appl. Polym. Sci. 102 (2006) 4690-4695.

[8] E. Hakansson, A. Kaynak, T. Lin, S. Nahavandi, T. Jones, E. Hu, Synth. Met. 144 (2004) 21-28.

[9] J.P. Boutrois, R. Jolly, C. Pétrescu, Synth. Met. 85 (1997) 1405-1406.

[10] H. Kuhn, A. Child, W. Kimbrell, Synth. Met. 71 (1995) 2139-2142. 
[11] D. Akbarov, B. Baymuratov, P. Westbroek, R. Akbarov, K. Declerck, P. Kiekens, J. Appl. Electrochem. 36 (2006) 411-418.

[12] T. Lin, L. Wang, X. Wang, A. Kaynak, Thin Solid Films 479 (2005) 77-82.

[13] F. Ferrero, L. Napoli, C. Tonin, A. Varesano, J. Appl. Polym. Sci. 102 (2006) $4121-4126$.

[14] S. Garg, C. Hurren, A. Kaynak, Synth. Met. 157 (2007) 41-47.

[15] J. Molina, A.I. del Río, J. Bonastre, F. Cases, Eur. Polym. J. 44 (2008) 2087-2098.

[16] H.S. Lee, J. Hong, Synth. Met. 113 (2000) 115-119.

[17] T. Patois, B. Lakard, N. Martin, P. Fievet, Synth. Met. 160 (2010) 2180-2185.

[18] E. Gasana, P. Westbroek, J. Hakuzimana, K. De Clerck, G. Priniotakis, P. Kiekens, D. Tseles, Surf. Coat. Tech. 201 (2006) 3547-3551.

[19] L. Dall'Acqua, C. Tonin, A. Varesano, M. Canetti, W. Porzio, M. Catellani, Synth. Met. 156 (2006) 379-386.

[20] L. Dall'Acqua, C. Tonin, R. Peila, F. Ferrero, M. Catellani, Synth. Met. 146 (2004) 213-221.

[21] K.G. Neoh, T.T. Young, E.T. Kang, K.L. Tan, J. Appl. Polym. Sci. 64 (1997) 519526.

[22] P. Gómez-Romero, J.A. Asensio, S. Borrós, Electrochim. Acta 50 (2005) 47154720.

[23] P. Gómez-Romero, M. Lira-Cantú, Adv. Mater. 9 (1997) 144-147.

[24] K. Bouzek, K.M. Mangold, K. Jüttner, J. Appl. Electrochem. 31 (2001) 501-507.

[25] L. Li, Y. Zhang, J.F. Drillet, R. Dittmeyer, K.M. Jüttner, Chem. Eng. J. 133 (2007) 113-119. 
[26] F.J. Rodríguez, S. Gutiérrez, J.S. Ibanez, J.L. Bravo, N. Batina, Environ. Sci. Technol. 34 (2000) 2018-2023.

[27] Y. Tian, J. Wang, Z. Wang, S. Wang, Synth. Met. 143 (2004) 309-313.

[28] A. Lopes, S. Martins, A. Moraö, M. Magrinho, I. Gonçalves, Port. Electrochim. Acta 22 (2004) 279-294.

[29] A.H. Gemeay, R.G. El-Sharkawy, I.A. Mansour, A.B. Zaki, Appl. Catal. B 80 (2008) 106-115.

[30] A.H. Gemeay, R.G. El-Sharkawy, I.A. Mansour, A.B. Zaki, J. Colloid. Interf. Sci. 308 (2007) 385-394.

[31] Complete textile glossary, available from: http://www.celaneseacetate.com/textile_glossary_filament_acetate.pdf, 2001. Last accessed 23 March 2011.

[32] W. Liang, J. Lei, C.R. Martin, Synth. Met. 52 (1992) 227-239.

[33] W.S. Subrahmanyam, S.K. Das, B.N. Ganguly, A. Bhattacharya, A. De, Mater. Res. Bull. 32 (1997) 1063-1072.

[34] N.V. Blinova, J. Stejskal, M. Trchová, J. Prokes, M. Omastová, Eur. Polym. J. 43 (2007) 2331-2341.

[35] R. Dygas, G. Fafilek, H. Durakpasa, M. W. Breiter, J. Appl. Electrochem. 23 (1993) 553-558.

[36] R. Friend, Nature 441 (2006) 37.

[37] K. Lee, S. Cho, S. H. Park, A. J. Heeger, C.-W. Lee, S.-H. Lee, Nature 441 (2006) $65-68$.

[38] P. Syed Abthagir, R. Saraswathi, Mater. Chem. Phys. 92 (2005) 21-26. 
[39] V. Shaktawat, N. Jain, R. Saxena, N.S. Saxena, K. Sharma, T.P. Sharma, Polym. Bull. 57 (2006) 535-543.

[40] M. Taunk, A. Kapil, S. Chand, J. Mater. Sci: Mater. Electron. 22 (2011) 136-142.

[41] M.A. Vorotyntsev, J.P. Badiali, E. Vieil, Electrochim. Acta 41 (1996) 1375-1381.

[42] T. Van Schaftinghen, C. Deslouis, A. Hubin, H. Terryn, Electrochim. Acta 51 (2006) 1695-1703.

[43] H. Nguyen Thi Le, B. Garcia, C. Deslouis, Q. Le Xuan, Electrochim. Acta 46 (2001) 4259-4272.

[44] M. Krzysztof, Electroanal. 18 (2006) 1537-1551.

[45] J.H. Hwang, M. Pyo, Synth. Met. 157 (2007) 155-159.

[46] W. Feng, T.R. Zhang, Y. Liu, R. Lu, Y.Y. Zhao, J.N. Yao, J. Mater. Sci. 38 (2003) 1045-1048.

[47] S.-X. Guo, A.W.A. Mariotti, C. Schlipf, A.M. Bond, A.G. Wedd, J. Electroanal. Chem. 591 (2006) 7-18. 


\section{Figure Captions}

Fig. 1. Molecular structure of phosphotungstic acid

Fig. 2. Idealized scheme of the structure of the molecular material formed between polypyrrole and $\mathrm{PW}_{12} \mathrm{O}_{40}{ }^{3-}$ anion.

Fig. 3. Photograph of GF-1000 sample cell (up to $1000{ }^{\circ} \mathrm{C}$ ): with water recirculation for cooling.

Fig. 4. Scheme of connections for impedance measurements with temperature.

Fig. 5. Bode plots for PES-PPy-POM fabric at different temperatures $\left(25-60{ }^{\circ} \mathrm{C}\right)$. Measurement between two Pt electrodes $\left(0.8 \mathrm{~cm}^{2}\right)$. Frequency range from $10^{4} \mathrm{~Hz}$ to $10^{-2}$ Hz.

Fig. 6. Plot of $\ln (\sigma)$ vs. 1000/T for the data obtained for a PES-PPy-POM fabric.

Fig. 7. Equivalent circuit for metal/PES-PPy-POM/electrolyte system.

Fig. 8. Nyquist plot of a hybrid organic-inorganic PES-PPy-POM fabric placed between two metallic conductors. Exposed electrode area: $1 \mathrm{~cm}^{2}$. Frequency range from $10^{4}$ to $10^{-2} \mathrm{~Hz}$ 
Fig. 9. Bode plots of a hybrid organic-inorganic PES-PPy-POM fabric placed between two metallic conductors. Exposed electrode area: $1 \mathrm{~cm}^{2}$. Frequency range from $10^{4}$ to $10^{-2} \mathrm{~Hz}$

Fig. 10. Simplified equivalent circuit for metal/PES-PPy-POM/electrolyte system.

Fig. 11. SEM micrographs of PES-PPy-POM fabrics treated in different $\mathrm{pH}$ solutions: a) $\mathrm{pH}$ 0, b) pH 7 and, c) pH 13.

Fig. 12. Nyquist plots of PES-PPy-POM fabrics immersed in different $\mathrm{pH}$ solutions in asymmetric configuration. Exposed electrode area: $1 \mathrm{~cm}^{2}$. Frequency range from $10^{4}$ to $10^{-2} \mathrm{~Hz}$

Fig. 13. Bode plots of PES-PPy-POM fabrics immersed in different $\mathrm{pH}$ solutions in asymmetric configuration. Exposed electrode area: $1 \mathrm{~cm}^{2}$. Frequency range from $10^{4}$ to $10^{-2} \mathrm{~Hz}$ 


\section{Table Captions}

Table 1

Results of the fitting of impedance data of PES-PPy-POM fabrics in different $\mathrm{pH}$ solutions: $\mathrm{pH} 0\left(0.5 \mathrm{M} \mathrm{H}_{2} \mathrm{SO}_{4}\right), \mathrm{pH} 7$ (phosphates buffer + $\left.0.1 \mathrm{M} \mathrm{Na}_{2} \mathrm{SO}_{4}\right), \mathrm{pH} 13(0.1$ $\mathrm{M} \mathrm{NaOH}+0.1 \mathrm{M} \mathrm{Na}_{2} \mathrm{SO}_{4}$ ). Resistance units in $\Omega \mathrm{cm}^{2}$ and capacitance units in $\mathrm{F} \mathrm{cm}^{-2}$. 


\begin{tabular}{cccc}
\hline PPy/POM fabrics & pH 0 & pH 7 & pH 13 \\
\hline Ren & 8 & 78 & 55 \\
\hline Rs & 6 & 62 & 38 \\
\hline Rf + Rmfe & 2 & 16 & 17 \\
\hline Rfsi & 4 & 13 & 58 \\
\hline Cfsi & $2.6 \cdot 10^{-5}$ & $1.9 \cdot 10^{-5}$ & $1.5 \cdot 10^{-5}$ \\
\hline W-R & 674 & 1191 & 3763 \\
\hline W-T & 175 & 186 & 2750 \\
\hline W-P & 0.7 & 0.8 & 0.5 \\
\hline Rfsie & 216 & 1064 & 1932 \\
\hline
\end{tabular}


Figure 1
Click here to download high resolution image

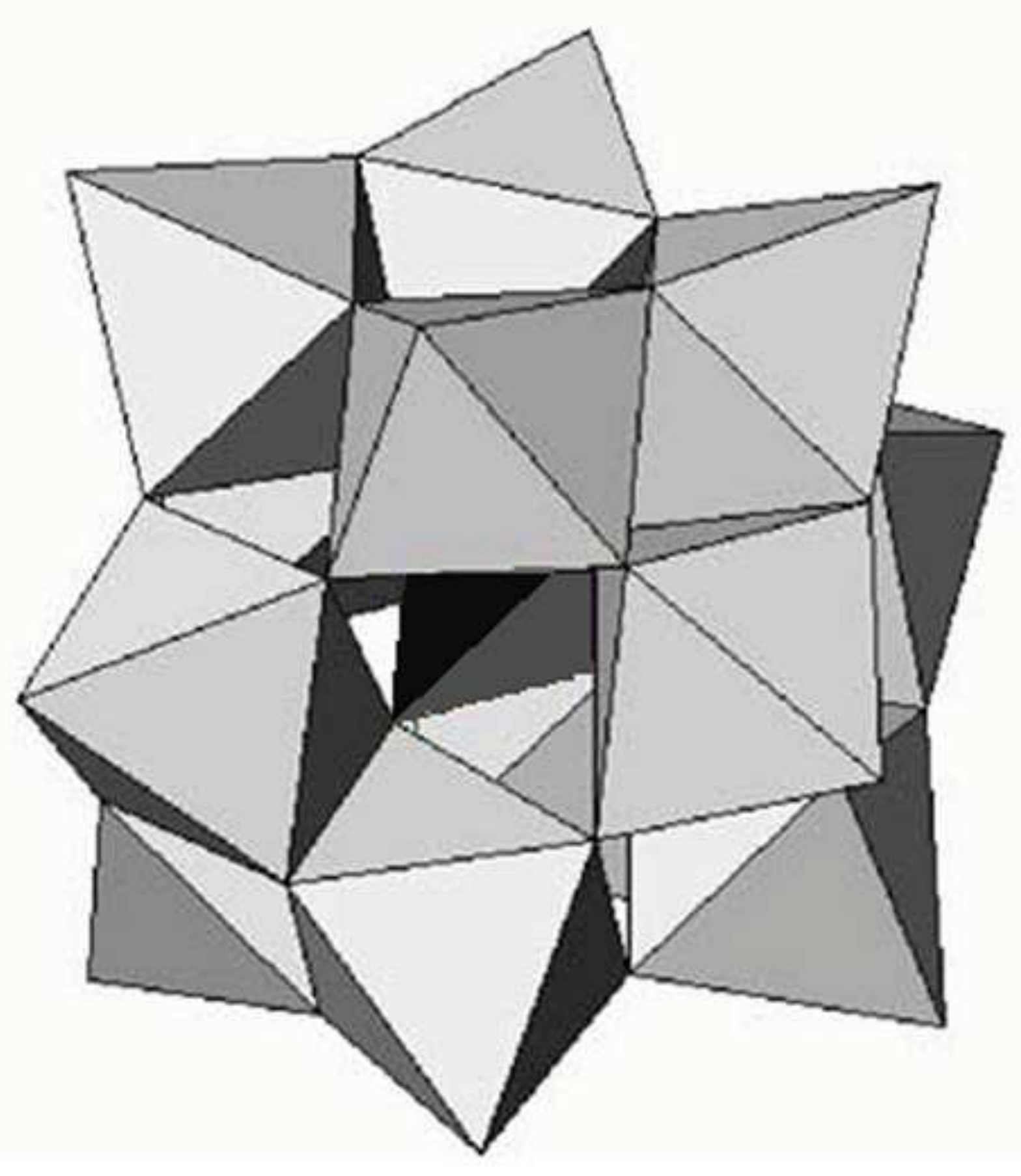



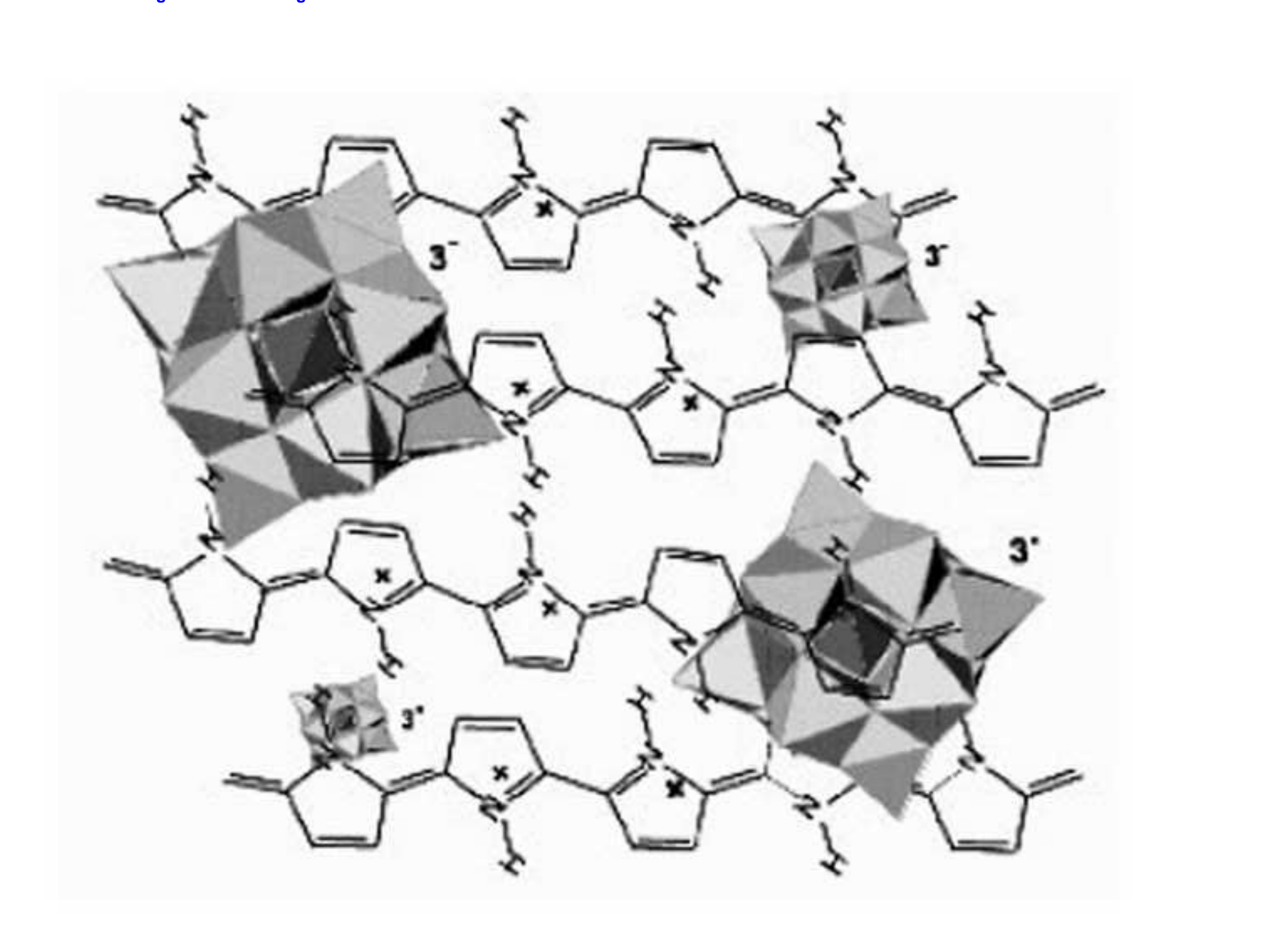


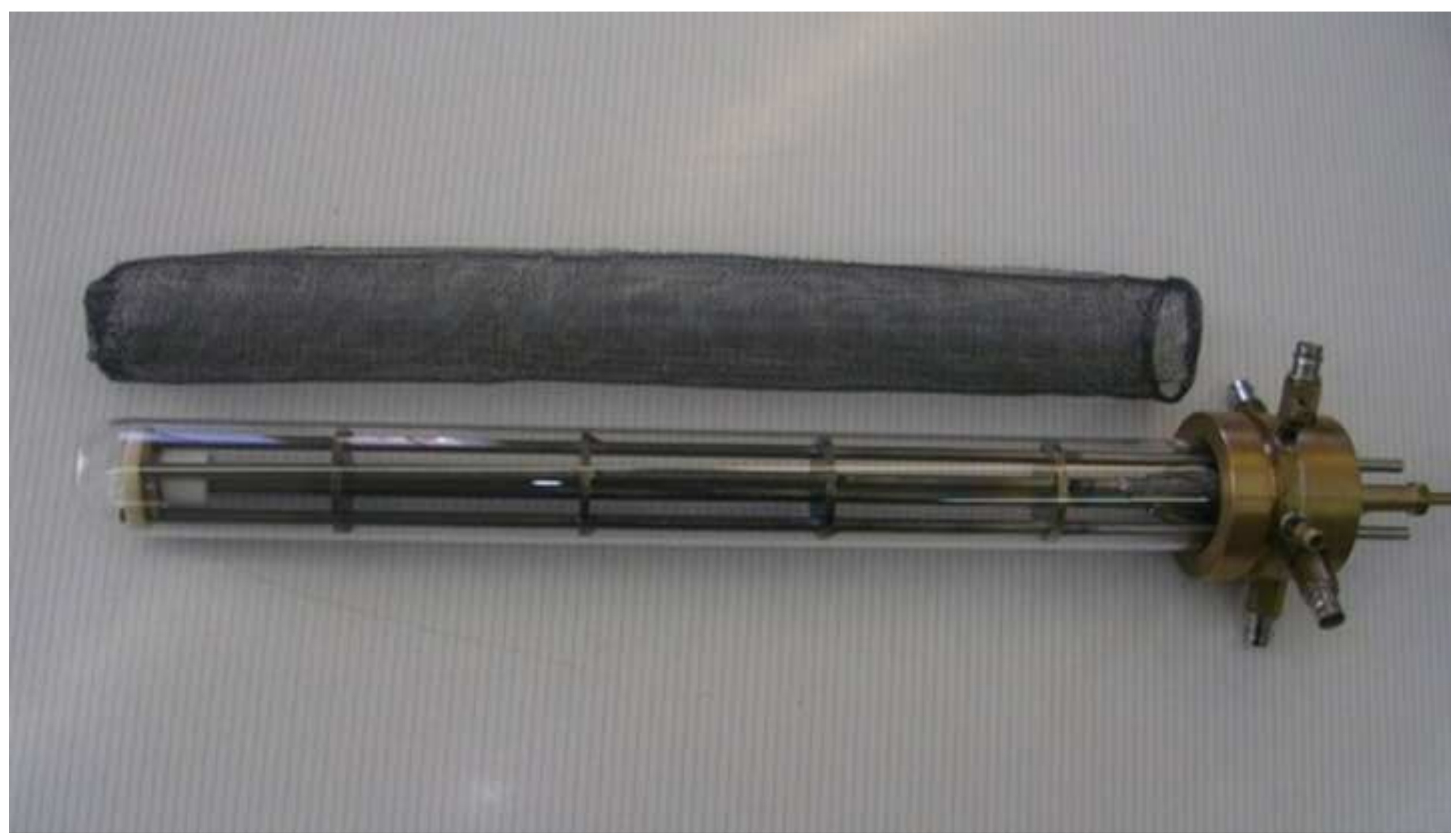




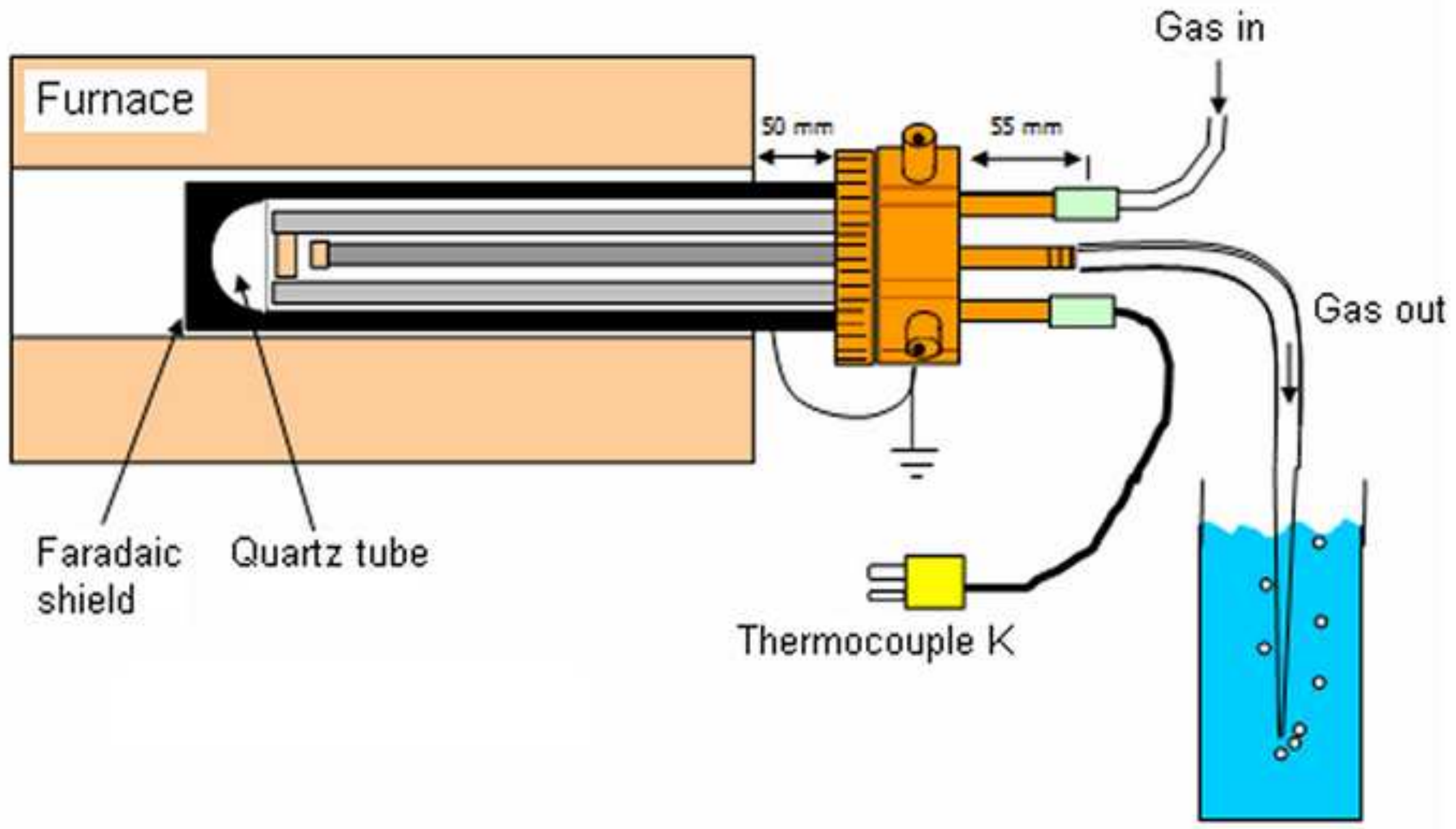



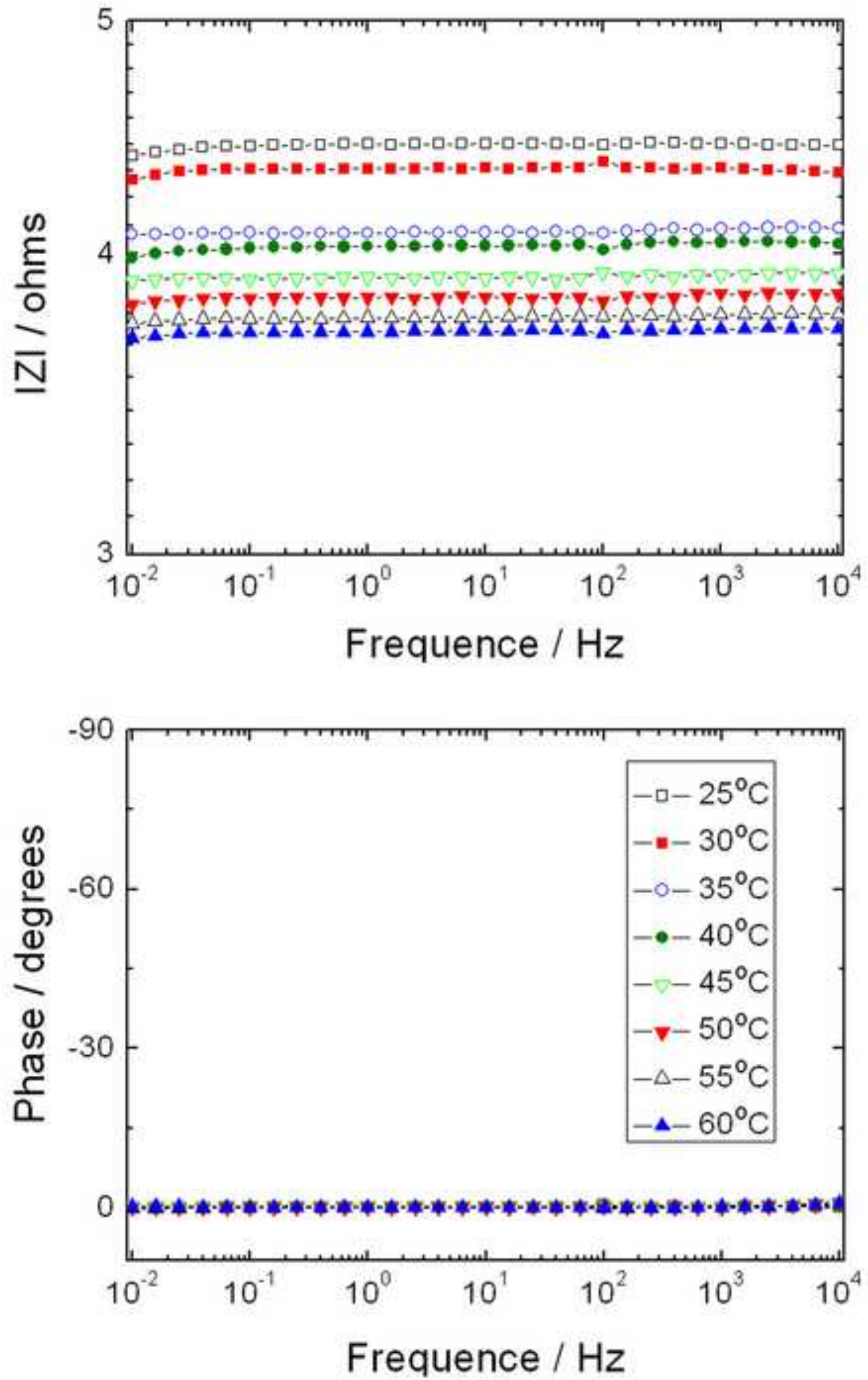
$\mathrm{T}\left({ }^{\circ} \mathrm{C}\right)$

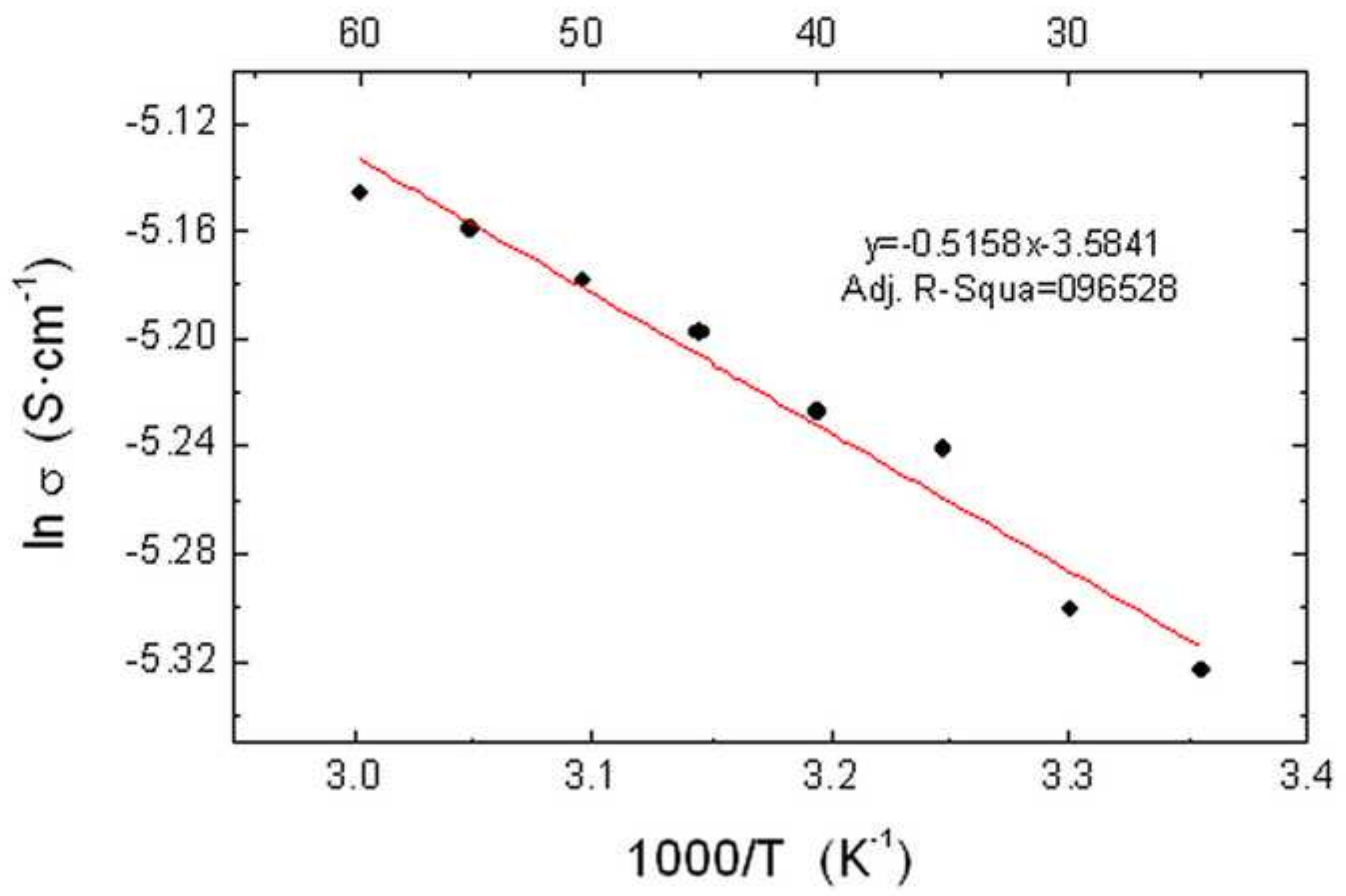




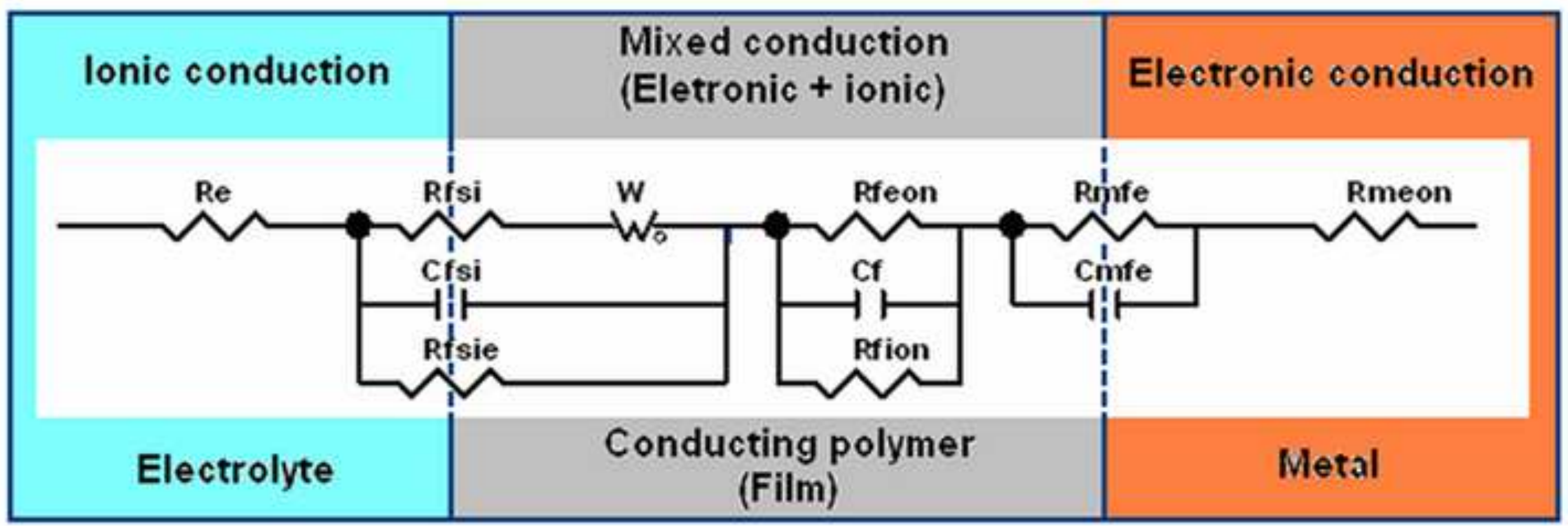




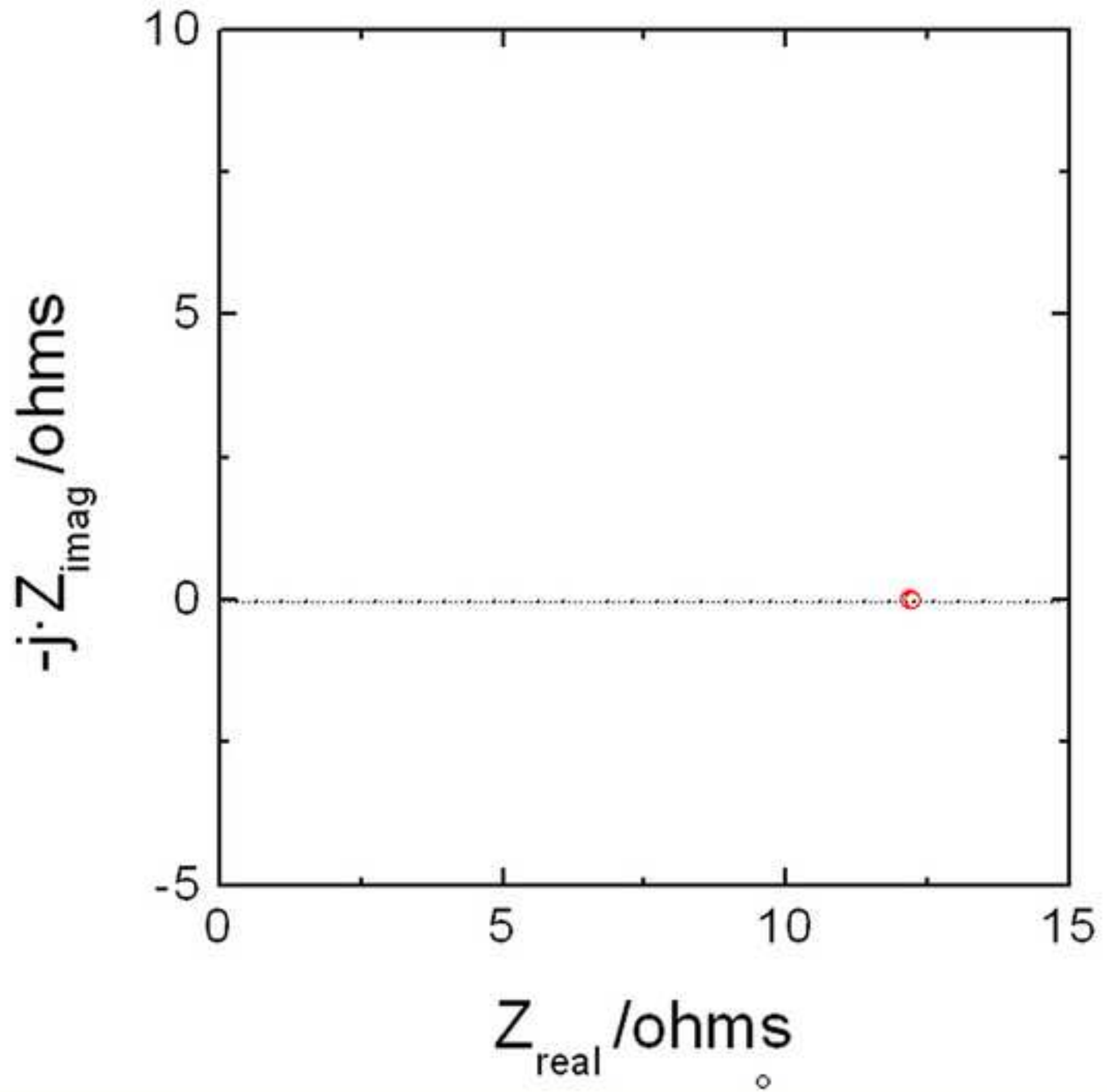



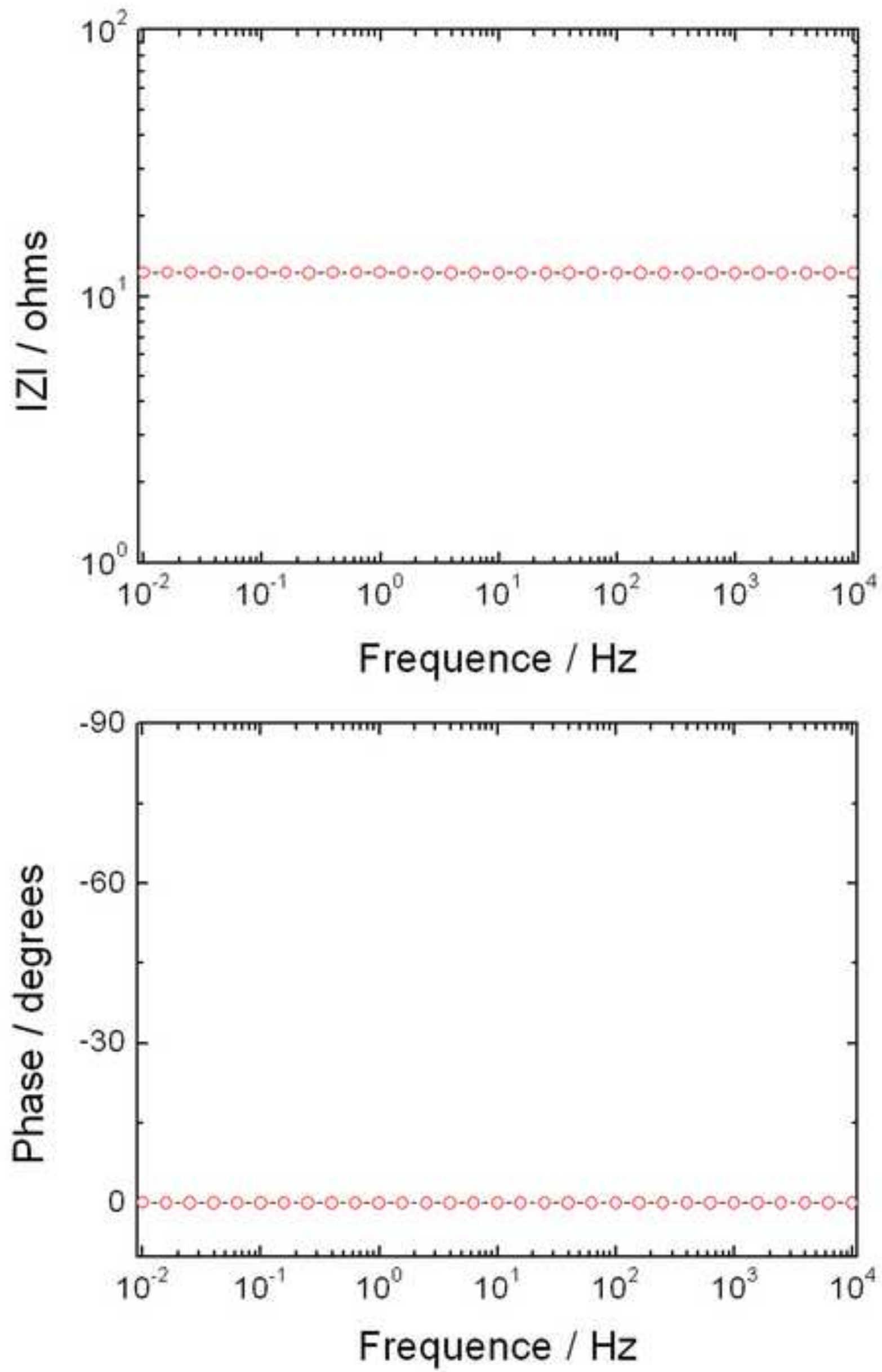


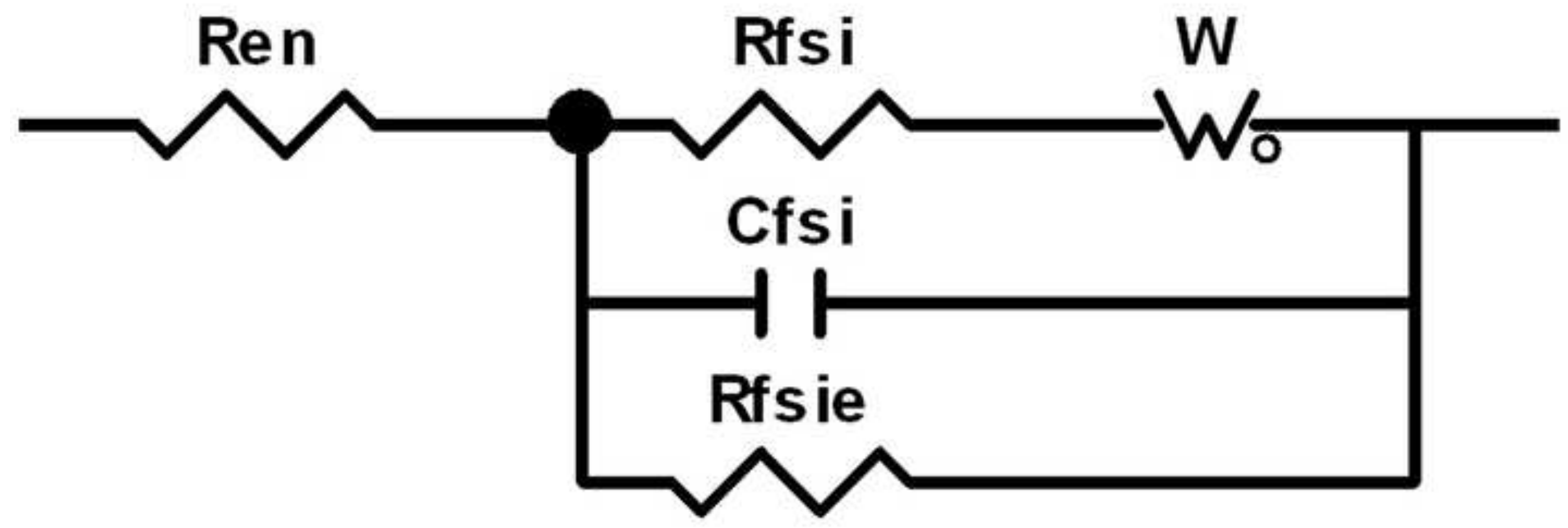




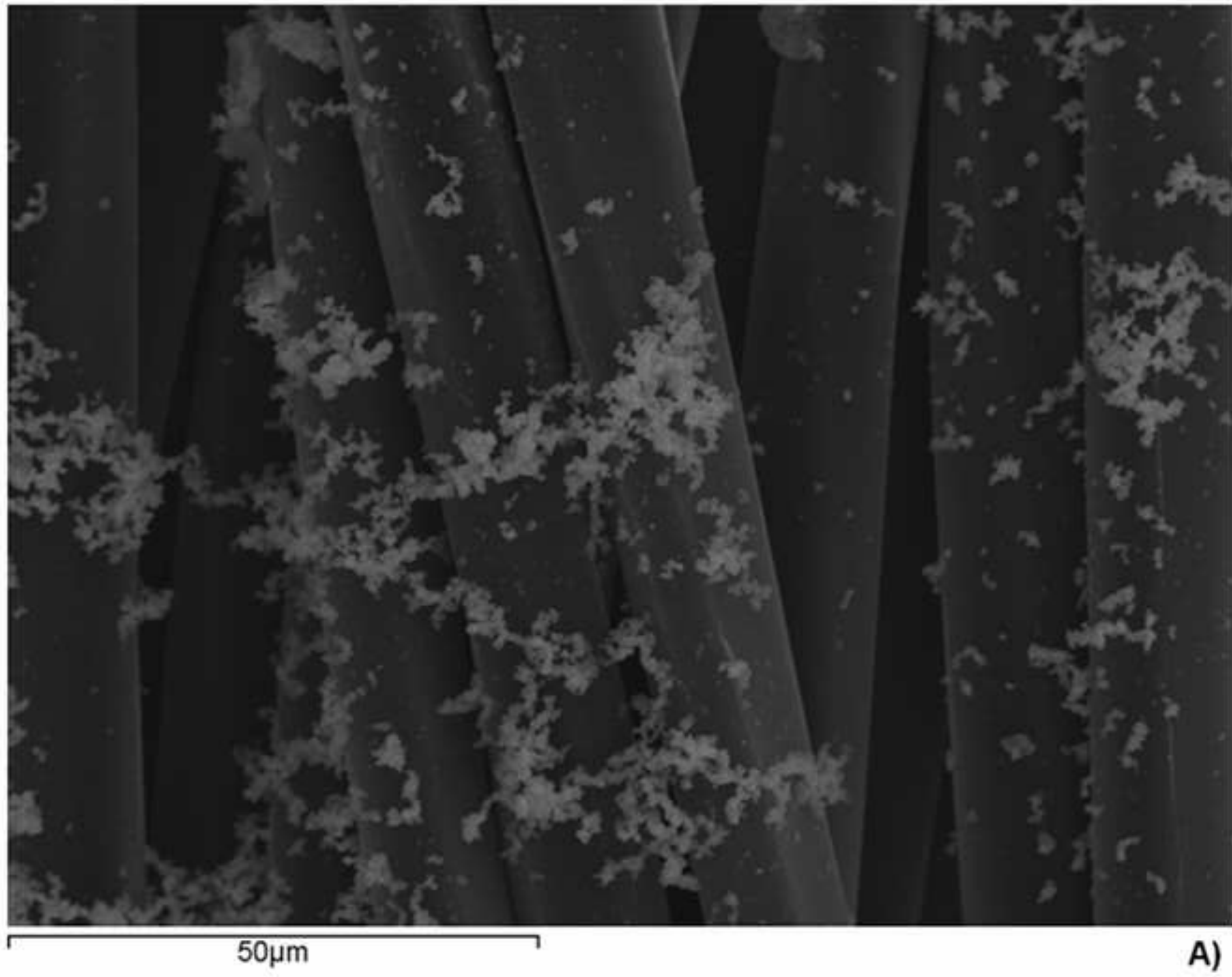




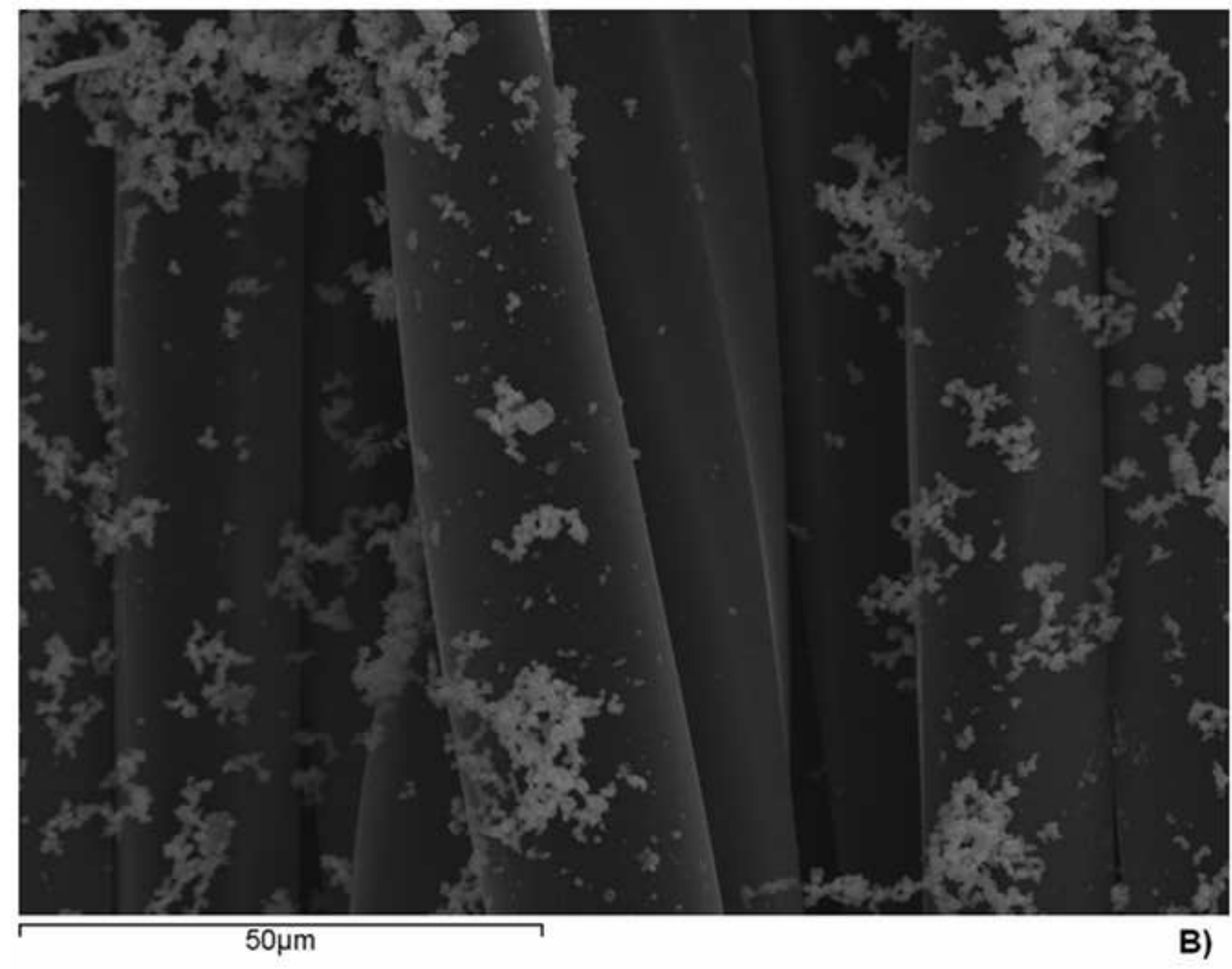

Click here to download high resolution image 
Click here to download high resolution image

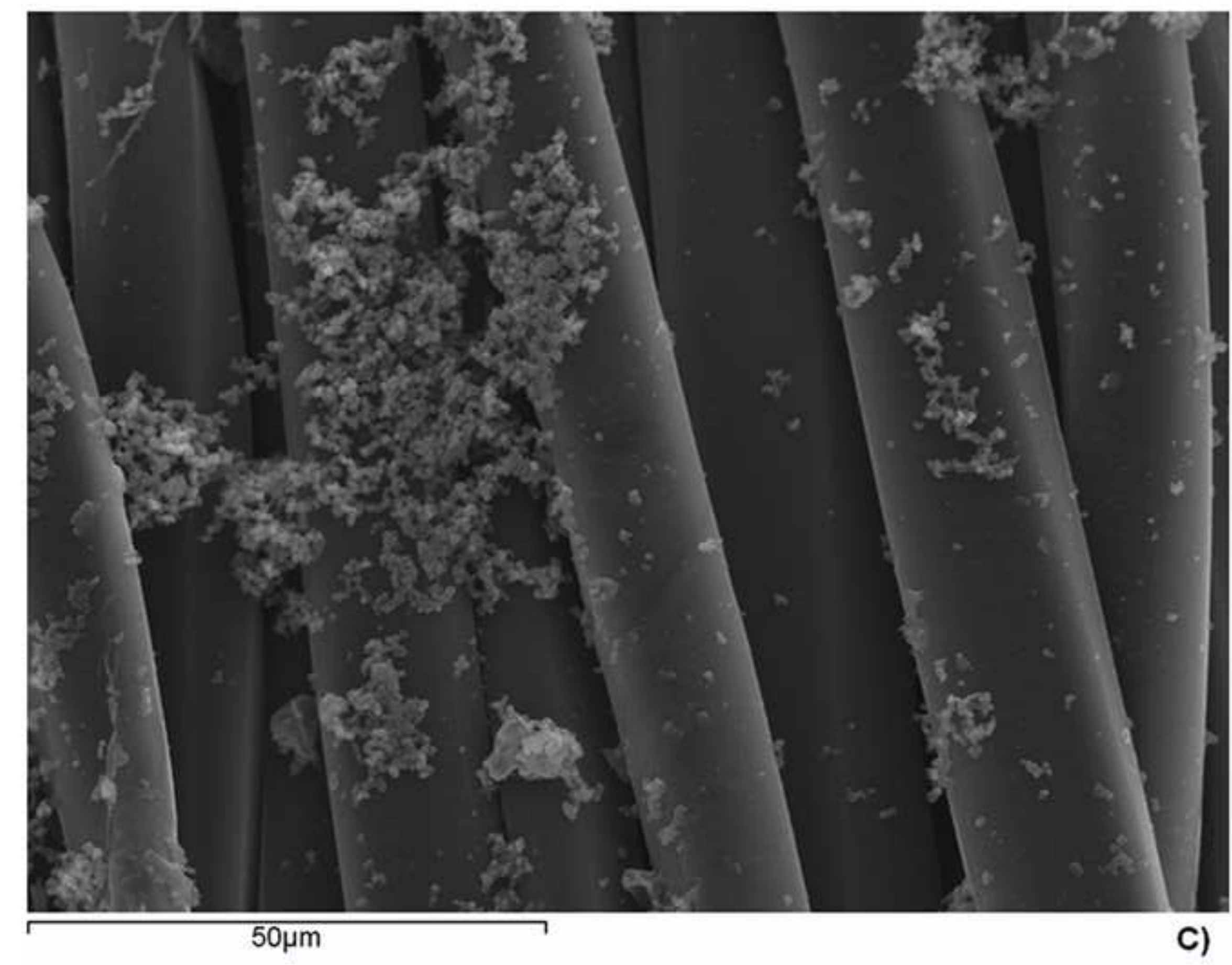

Click here to download high resolution image 


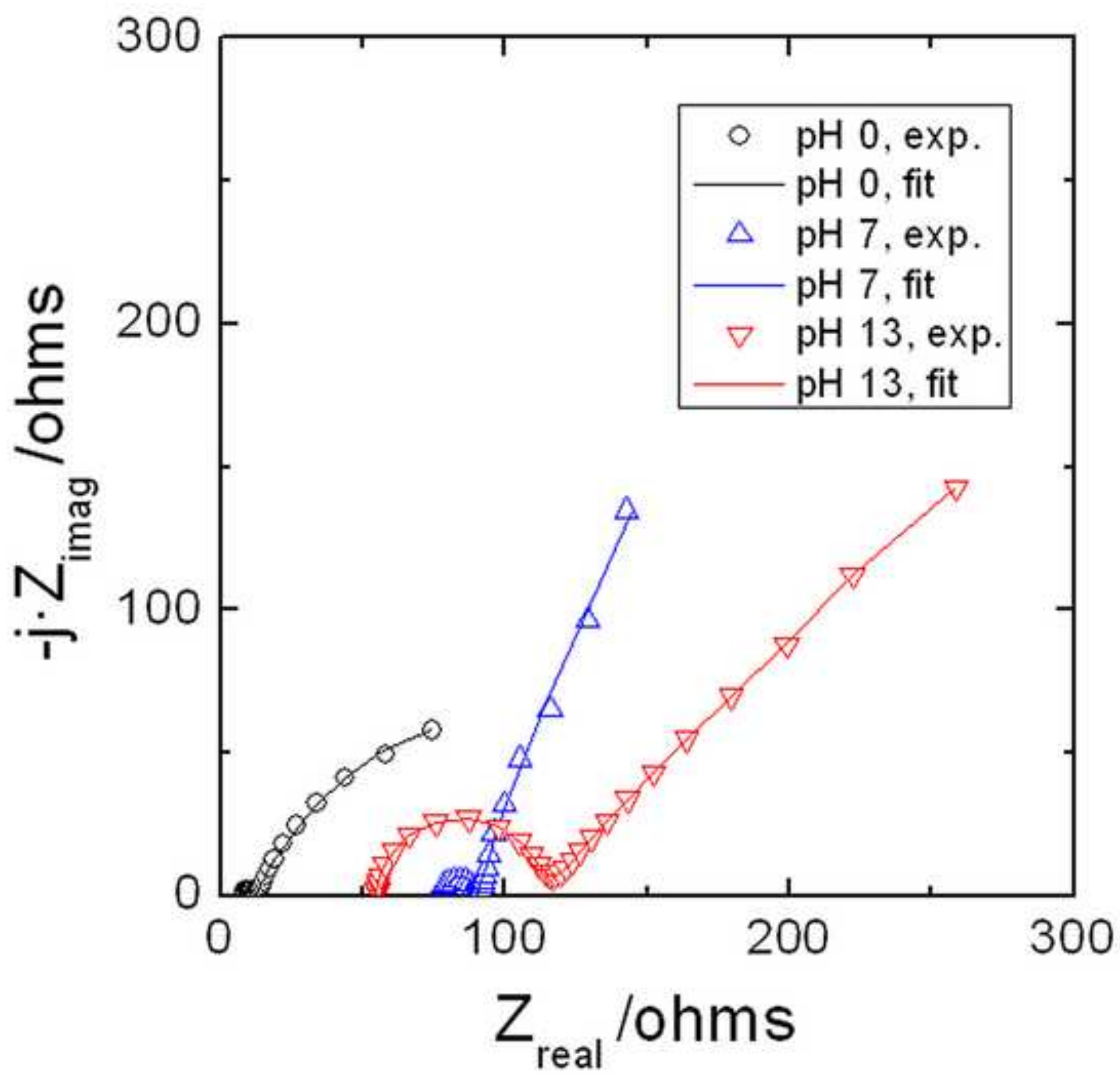



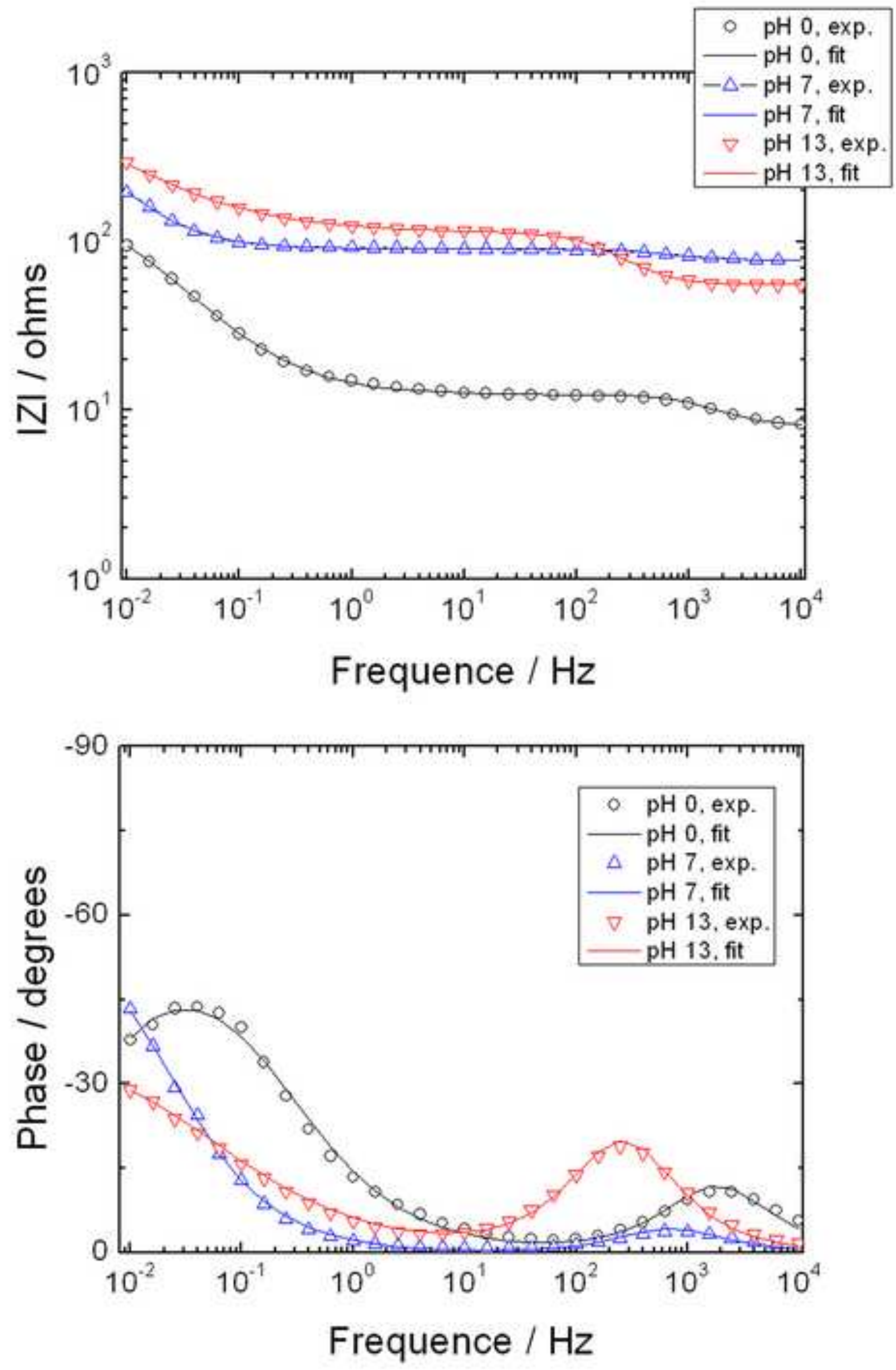